\title{
An international competition to predict the response of reinforced concrete panels
}

\author{
M. P. COLLINS \\ Department of Civil Engineering, University of Toronto, 35 St. George Street, Toronto, Ont., Canada M5S IA4 \\ F. J. VECCHIO \\ Civil Research Department, Ontario Hydro, 800 Kipling Avenue, Toronto, Ont., Canada M8Z 5 S4 \\ AND \\ G. MEHLHORN \\ Institut für Massivban, Technische Hochschule Darmstadt, Darmstadt, West Germany
}

Received March 14, 1985

Revised manuscript accepted May 23, 1985

\begin{abstract}
An international competition was organized to compare analytical methods for predicting the response of reinforced concrete elements subjected to general two-dimensional stress states. Four panels tested in a University of Toronto research program formed the subject of the competition. Entrants were asked to predict the panels' ultimate strength and load-deformation response, and to provide a brief description of the basis for their predictions.

Twenty-seven entries from thirteen countries were received. Predictions of ultimate strength were generally higher than the experimental values, and were marked by coefficients of variation of up to $40 \%$. Predicted strains were also much higher than observed, and had coefficients of variation of $50-100 \%$. The analytical methods used varied from simple hand calculations to complex finite element procedures.

This paper briefly reviews the physical properties, loading conditions, and observed response of the four test panels. Statistical details and general trends pertaining to the predictions received are discussed, and capsule summaries of the methods and assumptions used are presented.
\end{abstract}

Un concours international fut organisé afin de comparer les méthodes théoriques d'analyse du comportement d'éléments en béton armé sous un état biaxial de contraintes. Après avoir énoncé succintement les bases de leur calcul, les participants furent priés de prédire la résistance ultime et le diagramme charge-déformation de quatre panneaux testés lors d'un programme de recherche à l'université de Toronto.

Il y eut vingt-sept participants provenant de treize contrées différentes. Les valeurs obtenues pour la résistance ultime étaient généralement supérieures aux valeurs expérimentales, l'augmentation allant jusqu'à atteindre $40 \%$. Les valeurs des contraintes étaient également supérieures, de $50 \%$ à $100 \%$, aux valeurs mesurées. Les méthodes théoriques utilisées comprenaient des méthodes manuelles de calcul pour terminer par des méthodes par éléments finis.

L'article résume les propriétés mécaniques, les conditions de mise en charge et les résultats observés pour les quatre panneaux testés. Des détails statistiques et les tendances générales découlant des valeurs théoriques reçues sont discutées. Des sommaires des méthodes et hypothèses utilisées sont présentés.

[Traduit par la revue]

Can. J. Civ. Eng. 12, 624-644 (1985)

\section{Introduction}

Structures of the type shown in Fig. 1 carry load primarily through the action of in-plane stresses. To better understand the behaviour of such complex structures, it is necessary to first understand the response of simpler two-dimensional, rectangular, reinforced concrete elements subjected to uniform plane stresses.

Predicting the response of a reinforced concrete panel subjected to plane stresses would appear to be a basic and simple calculation. Unfortunately, this is not the case. A diverse number of theories and calculation pro-

NoTE: Written discussion of this paper is welcomed and will be received by the Editor until December 31, 1985 (address inside front cover). cedures have been proposed, ranging from plasticity models to complex finite element analyses. While most are based on firm theoretical concepts, the varying assumptions made regarding material response and physical modelling result in a wide scatter of predicted strengths and load-deformation responses. Experimental data necessary for calibrating the various analytical procedures has been lacking.

In an attempt to obtain the needed experimental data, a research program was recently conducted at the University of Toronto (Vecchio and Collins 1982). This program involved testing reinforced concrete panels under a variety of well-defined, uniform stresses in a specially constructed test rig (see Fig. 2).

The panels were loaded by forces applied to 20 steel 


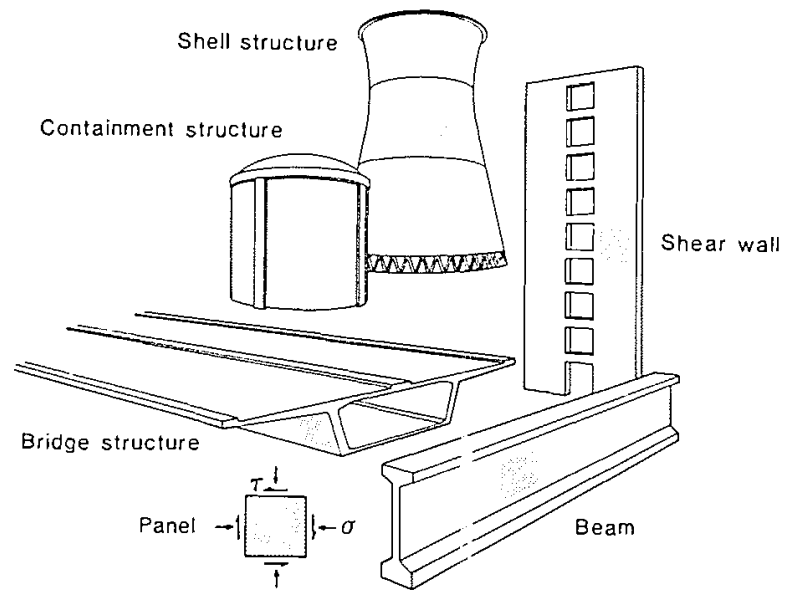

FIG. 1. Panels in reinforced concrete structures.

'shear keys,' which were anchored into the perimeter edges of the specimen (see Fig. 3). Attached to each shear key were two 'links' (one at $45^{\circ}$ to either side of the normal); the link network, in turn, was connected to a series of $37220 \mathrm{kN}$ double-acting hydraulic jacks. The remaining three links were rigid so as to stabilize the panel within the test rig. By varying the magnitude and direction of the forces in the links, any combination of shear and tension or compression could be applied to the test specimen.

A preliminary report, which included a description of the new test rig and a summary of the first 16 panel tests, was presented at the International Association for Bridge and Structural Engineering Colloquium on the Advanced Mechanics of Reinforced Concrete at Delft in June of 1981 (Vecchio and Collins 1981). The Chairman of the appropriate session at Delft, Prof. Schnobrich of the University of Illinois, suggested that future tests on the University of Toronto rig might offer a valuable chance to evaluate the ability of existing analytical methods to predict behaviour.

An outcome of the discussions at Delft was an international competition to predict the behaviour of four panels tested at the University of Toronto in August, 1981. Details of the specimen construction, material properties, and loading conditions were made public but the results of the tests were kept confidential until after the closing date (December 1981) of the competition.

Entry forms were sent to all participants of the Delft Colloquium as well as to many other researchers involved in modelling reinforced concrete behaviour. The response to the competition was favourable, with many of the foremost researchers in the field being represented. A total of 27 entries from 13 different countries was received. Of these, 20 submitted predictions of deformation response in addition to making strength predictions. In this paper, the results of the prediction competition will be summarized and some lessons will be drawn from the results.

\section{The four test panels}

The concrete test panels were $890 \mathrm{~mm}$ square by 70 $\mathrm{mm}$ thick. They were reinforced with two layers of welded wire mesh, with the wires running parallel to the edges of the panels. The smooth wire meshes had a $50 \mathrm{~mm}$ grid spacing, were heat-treated, and showed ductile response. A clear cover of $6 \mathrm{~mm}$ was provided.

The four specimens selected for the prediction competition were identified as panels A, B, C, and D. As part of the overall test program (Vecchio and Collins 1982), they corresponded to panels PV27, PV25, PV 19, and PV29, respectively. The concrete and reinforcement properties, and loading conditions for each are given in Fig. 4. Participants were requested to predict the failure loads for each panel and the corresponding deformations at $25 \%, 50 \%, 75 \%$, and $100 \%$ of failure loads.

Panel A was isotropically reinforced $\left(\rho_{x}=\rho_{y}\right)$ and was loaded in pure shear. It was a heavily reinforced panel $\left(\rho_{x} \simeq 0.02, \rho_{\mathrm{x}} f_{\mathrm{y}} / f_{\mathrm{c}}^{\prime} \simeq 0.04\right)$ and hence failure could be expected by crushing of the concrete prior to yielding of the reinforcement. The intention was to check the ability of the available models to predict such failures by concrete crushing.

Panel B was nominally identical to panel A except that it was subjected to combined biaxial compression and shear. If a panel is failing by crushing of the concrete, will adding biaxial compression weaken the panel or strengthen the panel? The intention was to see how the participants answered this question.

Panel $\mathrm{C}$, tested in pure shear, was nonisotropically reinforced $\left(\rho_{x}=2.5 \rho_{y}\right)$. Here the challenge was to predict the load at which the weaker steel would yield and how this yielding would influence subsequent behaviour.

Panel D was also nonisotropically reinforced $\left(\rho_{r} \simeq\right.$ $2 \rho_{y}$ ) but was subjected to nonproportional loading. The panel was initially loaded in pure shear up to a stress of 3.9 MPa. Further increments in shear stress were accompanied by biaxial compressive stresses of equal magnitude. Here the question was how successfully could the methods account for load history.

It should be emphasized that in selecting four panels for the prediction competition, the authors deliberately chose panels whose behaviour would be difficult to predict. In none of the panels was the load capacity governed by simple yielding of the reinforcement; hence, the predictions were strongly dependent on the assumed stress - strain characteristics of the concrete. The panels were chosen with Rüsch's (1960) comment in mind; "Only tests of over-reinforced members 


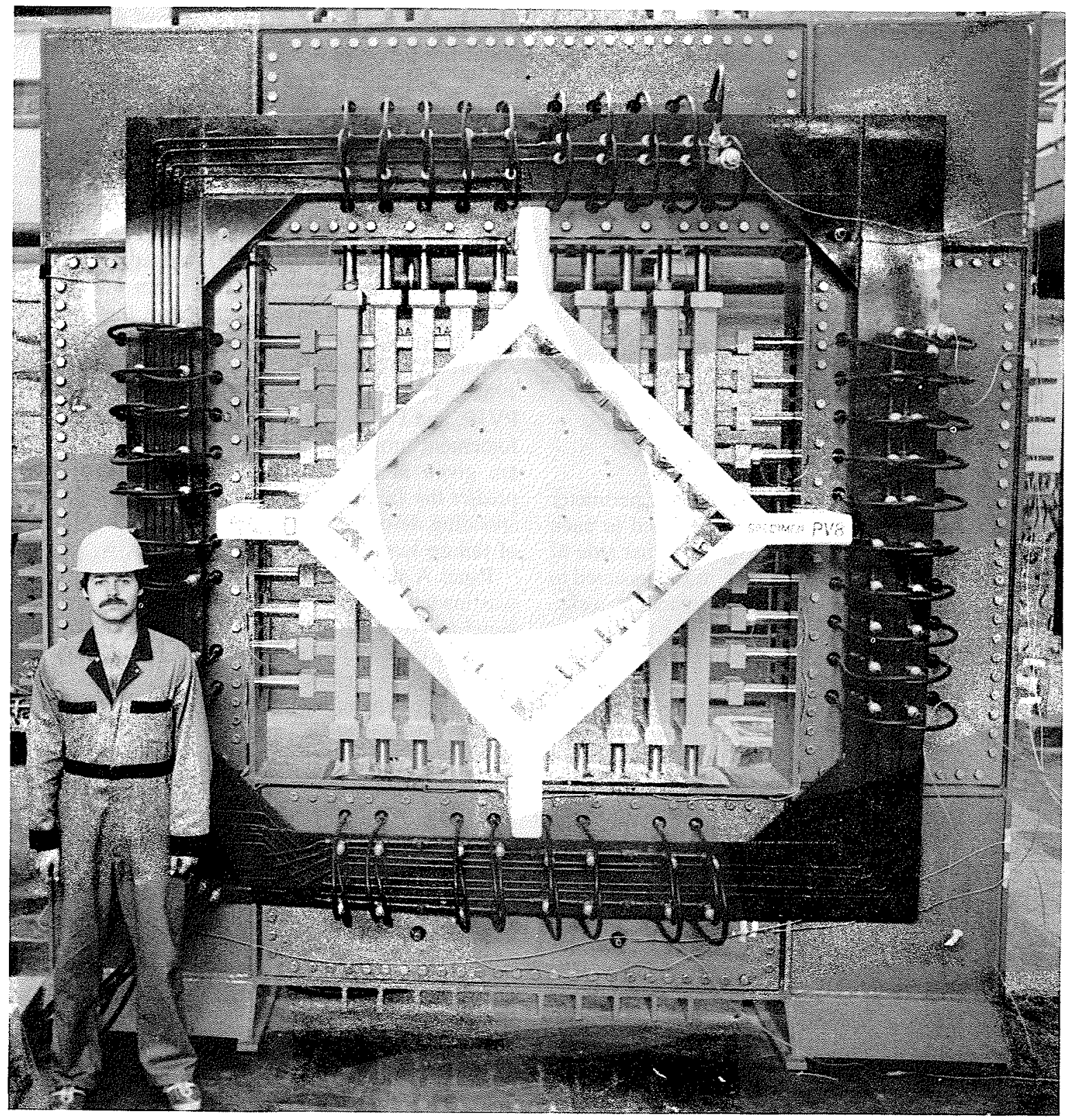

FIG. 2. Loading system for testing reinforced concrete panels.

can furnish a true measure of the validity of a flexural theory."

\section{Comparison of observed and predicted strengths}

Table 1 and Fig. 5 compare the observed and predicted strengths of the four panels. A summary of the analytical procedures used to arrive at the various predictions is provided in Appendix 2.

Panel A failed at a shear stress of $6.3 \mathrm{MPa}$ in a sliding failure of the concrete parallel to the $x$ reinforcement (see Fig. 6). Neither the $x$ nor the $y$ reinforcement had yielded prior to failure. Predictions for the strength of panel A ranged from 4.4 to $8.8 \mathrm{MPa}$, with a mean value of 7.2 MPa and a standard deviation of 1.2 MPa. The coefficient of variation of the predicted to observed values, at $17 \%$, was the lowest of the four panels. The closest estimates were submitted by Bažant and Oh at $6.4 \mathrm{MPa}$ and by Červenka at $6.2 \mathrm{MPa}$. Note that predictions based on neglecting tensile stresses in the concrete and assuming yield of the reinforcement had a value of 


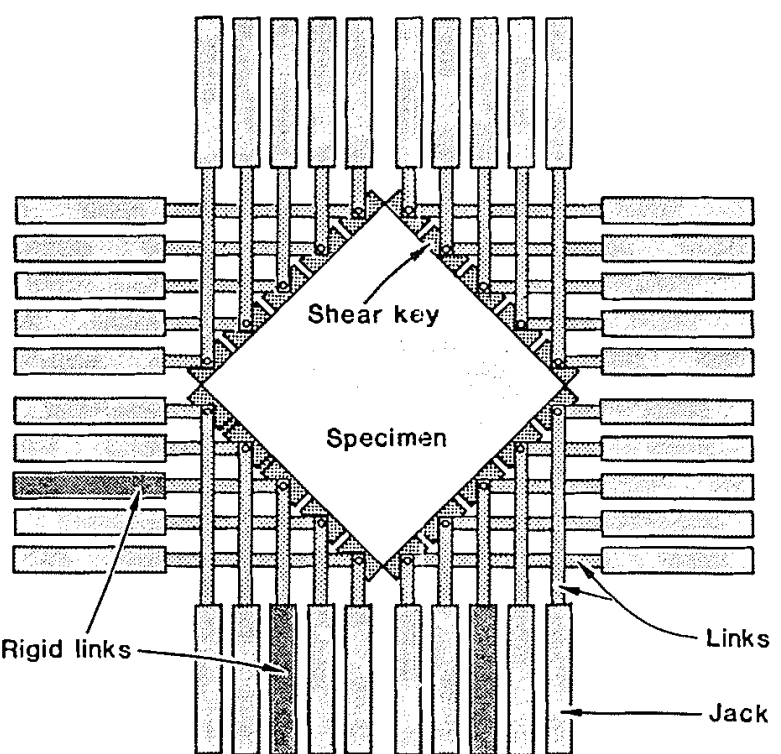

FIG. 3. Details of loading system.

7.9 MPa (i.e. predicted/observed value of 1.3).

Panel B failed at $9.1 \mathrm{MPa}$ in a very brittle sliding failure of the concrete parallel to the $x$ reinforcement (see Fig. 7). Again, neither reinforcement had yielded prior to failure. It is important to note that the biaxial compression caused an increase in shear capacity of about $45 \%$. Nineteen of the twenty-seven entries predicted that panel B would be stronger than panel A with predicted strength increases ranging from $7 \%$ to $158 \%$. Seven of the entries predicted that biaxial compression would reduce the shear strength, with predicted decreases ranging from $3 \%$ to $69 \%$. Strength predictions for panel $\mathrm{B}$ ranged from 2.5 to $15.2 \mathrm{MPa}$ with a mean value of $8.7 \mathrm{MPa}, 5 \%$ lower than the observed value. The closest estimate was made by Walter and Mang, predicting a shear strength of $9.0 \mathrm{MPa}$.

Panel C failed at $4.0 \mathrm{MPa}$ after yielding of the weaker $y$ reinforcement just prior to yielding of the $x$ reinforcement. The failure, which involved crushing and sliding of the concrete (see Fig. 8), was very gradual. Predictions for the strength of panel $\mathrm{C}$ ranged from 2.1 to $5.7 \mathrm{MPa}$ with a mean of $4.1 \mathrm{MPa}$ and a coefficient of variation of $22 \%$. Eight of the entrants predicted a strength of $4.2 \mathrm{MPa}$, the value obtained if tensile stresses in the concrete are neglected and the reinforcement is assumed to yield at failure. It should be noted that the accuracy of this full yield prediction is somewhat a matter of chance. For example, if the yield strength of the $x$ reinforcement had been $558 \mathrm{MPa}$ rather than $458 \mathrm{MPa}$, the failure load of the panel would have been the same (the $x$ steel did not yield). However, the full yield prediction would have increased to $4.6 \mathrm{MPa}$.
Accurate predictions for the strength and mode of failure of panel $\mathrm{C}$ were provided by Kanellopoulos, Marti, and Thürlimann at $4.0 \mathrm{MPa}$ and Bažant and $\mathrm{Oh}$ at $3.9 \mathrm{MPa}$.

Panel $D$ was first loaded in pure shear to a shear stress of 3.9 MPa. At this load the weaker $y$ reinforcement just yielded and there were some small signs of ridging and spalling of the concrete, indicating that failure was close if the pure shear loading was increased. However, by applying biaxial compression as the shear was increased, it proved possible to substantially increase the shear applied to the panel. At a shear of $5.9 \mathrm{MPa}$ and a biaxial compression of $2.1 \mathrm{MPa}$ (i.e. $\sigma_{x}=\sigma_{y}=-2.1 \mathrm{MPa}$ ) a sudden sliding failure of the concrete occurred (see Fig. 9). The $x$ reinforcement did not yield. Panel D produced the widest scatter in estimates of failure shear. Predictions ranged from 3.4 $\mathrm{MPa}$ to $16.5 \mathrm{MPa}$ with a mean of $8.1 \mathrm{MPa}$ and a coefficient of variation of $40 \%$. The most accurate predictions were made by Razaqpur and Ghali (6.0 MPa) and by Červenka (5.7 MPa).

\section{Comparison of observed and predicted deformations}

The predicted values of normal and shear strain $\left(\epsilon_{x}\right.$, $\left.\epsilon_{y}, \alpha_{x y}\right)$, at $25 \%, 50 \%, 75 \%$, and $100 \%$ of the predicted failure load, are summarized in Tables $2-5$. Also given in these tables are experimentally observed values. Figures 10-12 compare the observed and predicted load-deformation responses.

The predicted load-deformation responses approximately follow the general trend of the observed stressstrain curves. However, some systematic errors can be recognized. For example:

(i) The observed response at low stress levels was much stiffer than predicted, suggesting that the contribution from the concrete tensile strength was underestimated.

(ii) After cracking, the observed deformation response was still generally stiffer than predicted; this suggested that the effects of tension stiffening were also underestimated.

(iii) Panel A showed much less ductility than predicted at ultimate stress levels.

(iv) The behaviour of panel D was very poorly predicted, suggesting that the effects of nonproportional loading were not well understood.

As might be expected, estimates of strains showed much more scatter than those of ultimate strength. The coefficients of variation were in the order of $100 \%$ at low stress levels, and $25-50 \%$ at moderate to high stress levels. The scatter of predictions was particularly large for panels $B$ and $D$.

Predictions received were quite erratic as a whole, although some fine entries were among them. Three of 

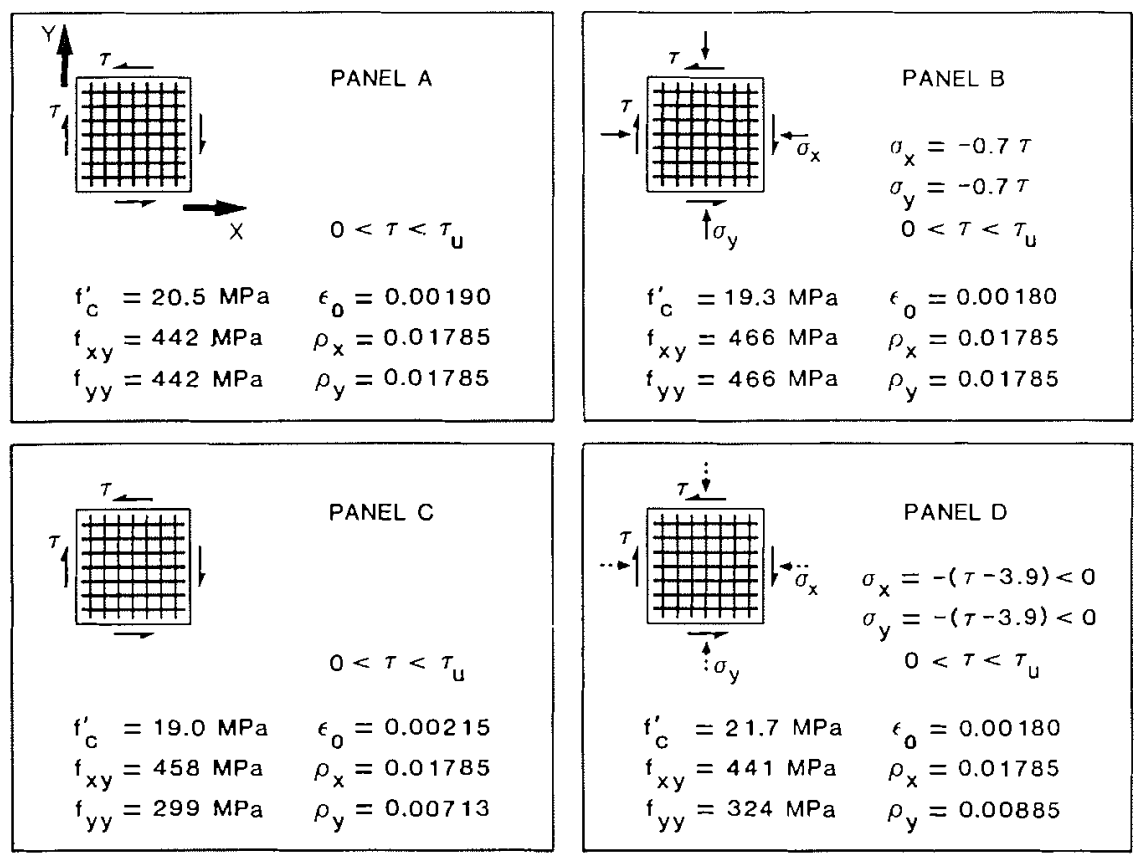

FIG. 4. Material properties and loading conditions for the four test panels.
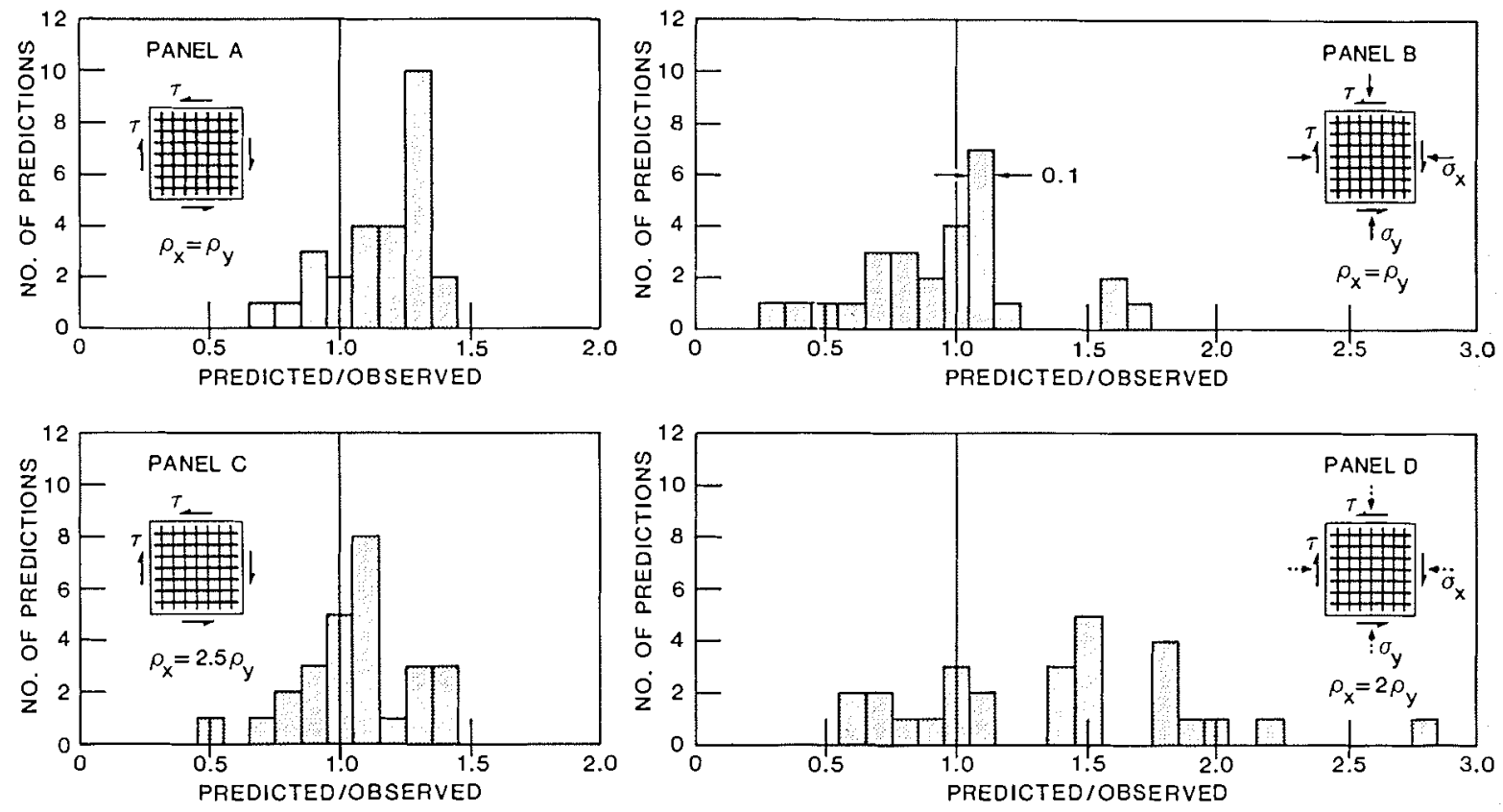

FIG. 5. A schematic representation of the scatter in predicted strengths.

the better sets of predictions were submitted by Maekawa and Okamura, Cervenka, and Hillerborg; these are compared with the test results in Figs. 13-15. It is of interest to note that radically different approaches were employed in producing these three entries.
Maekawa and Okamura based their estimates on the results of a complex nonlinear finite element analysis, using a program developed by NAPRA (Nonlinear Analysis Program Research Association, University of Tokyo). The program incorporates a kinematic strain- 
TABLE 1. Predicted Failure Shear Stresses

\begin{tabular}{|c|c|c|c|c|c|c|c|}
\hline \multirow{2}{*}{$\begin{array}{l}\text { Entry } \\
\text { No. }\end{array}$} & \multirow{2}{*}{ Authors } & \multirow{2}{*}{ Organization } & \multirow{2}{*}{ Country } & \multicolumn{4}{|c|}{$\begin{array}{c}\text { Predicted } \underset{(\mathrm{MPa})}{ } \\
\end{array}$} \\
\hline & & & & A & B & $\mathrm{C}$ & $\mathrm{D}$ \\
\hline 1 & Bažant \& Oh & Northwestern U. & U. S. A. & 6.4 & 10.4 & 3.9 & 11.5 \\
\hline 2 & Bazzi & ETH-Zurich & Switzerland & 7.9 & 9.6 & 4.2 & 10.8 \\
\hline 3 & Blaauwendraad \& Merks & Rijkswaterstaat & Netherlands & 4.4 & 5.6 & 3.8 & 3.9 \\
\hline 4 & Braestrup & TH-Denmark & Denmark & 7.7 & 7.2 & 4.2 & 8.0 \\
\hline 5 & Črvenka & 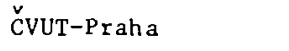 & Czechos lovakia & 6.2 & 7.9 & 3.3 & 5.7 \\
\hline 6 & Chang & U. of Akron & U. S. A. & 8.0 & 9.4 & 3.5 & 10.4 \\
\hline 7 & Gerstle & U. of Colorado & U. S. A. & 7.0 & 10.8 & 2.1 & 9.0 \\
\hline 8 & Gupta \& Akbar & $\begin{array}{l}\text { North Carolina } \\
\text { State U. }\end{array}$ & U. S. A. & 4.8 & 3.9 & 3.1 & 3.7 \\
\hline 9 & Hillerborg & $\begin{array}{l}\text { Lund Inst. of } \\
\text { Technology }\end{array}$ & Sweden & 7.2 & 7.0 & 4.2 & 6.2 \\
\hline 10 & Hilmy & Cornel1 U. & U. S. A. & 5.9 & 15.2 & 4.1 & 4.1 \\
\hline 11 & $\begin{array}{l}\text { Kamerling, Vlugt, } \\
\text { Fijneman \& Mier }\end{array}$ & TH-Eindhoven & Netherlands & 7.9 & 14.5 & 4.2 & 16.5 \\
\hline 12 & $\begin{array}{l}\text { Kane } 1 \text { lopoulos, Marti } \\
\& \text { Thirlimann }\end{array}$ & ETH-Zurich & Switzerland & 7.5 & 8.0 & 4.0 & 6.5 \\
\hline 13 & Klein & U. of Illinois & U. S. A. & 8.5 & 10.2 & 5.7 & 10.5 \\
\hline 14 & Kolmar \& Mehlhorn & TH-Darmstadt & Germany & 8.6 & 9.9 & 5.5 & 10.9 \\
\hline 15 & Kotsovos \& Bedard & Imperial College & U. $\mathrm{K}$. & 5.6 & 8.8 & 4.2 & 9.0 \\
\hline 16 & Maekawa \& Okamura & U. of Tokyo & Japan & 5.6 & 6.3 & 3.7 & 5.6 \\
\hline 17 & $\begin{array}{l}\text { Noguchi, Naganuma } \\
\& \text { Hagiwara }\end{array}$ & Chiba U. & Japan & 7.4 & 14.7 & 3.5 & 13.1 \\
\hline 18 & 01 sen & $\begin{array}{l}\text { Dr. Techn. } \\
\text { Olav Olsen }\end{array}$ & Norway & 7.9 & 6.5 & 4.2 & 8.6 \\
\hline 19 & Pajari & $\begin{array}{l}\text { Tech. Res. Centre } \\
\text { of Finland }\end{array}$ & Finland & 7.7 & 7.7 & 5.1 & 8.4 \\
\hline 20 & Razaqpur \& Ghali & U. of Calgary & Canada & 7.0 & 4.8 & 5.4 & 6.0 \\
\hline 21 & Reineck & U. of Stuttgart & Germany & 6.8 & 6.4 & 4.2 & 8.3 \\
\hline 22 & Schäfer & U. of Stuttgart & Germany & 8.8 & 10.0 & 5.2 & 10.8 \\
\hline 23 & $\begin{array}{l}\text { Schmidt-Gönner } \\
\& \text { Mehlhorn }\end{array}$ & TH-Darmstadt & Germany & 8.3 & 9.8 & 5.1 & 8.7 \\
\hline 24 & Shirai & Nihon U. & Japan & 8.1 & 2.5 & 3.8 & 4.9 \\
\hline 25 & Walraven \& Reinhardt & $\mathrm{TH}-\mathrm{De} \mathbf{l} \mathrm{ft}$ & Netherlands & 7.9 & 9.7 & 4.7 & 8.7 \\
\hline 26 & Walter \& Mang & TU-Wien & Austria & 8.4 & 9.0 & 2.6 & 3.4 \\
\hline \multirow[t]{6}{*}{27} & Weischede & U. of Stuttgart & Germany & 7.9 & 8.7 & 4.2 & 5.0 \\
\hline & & Range of Predicted & Values - Low & 4.4 & 2.5 & 2.1 & 3.4 \\
\hline & & & $-\mathrm{High}$ & 8.8 & 15.2 & 5.7 & 16.5 \\
\hline & & Mean & & 7.2 & 8.7 & 4.1 & 8.1 \\
\hline & & Standard Deviation & & \pm 1.2 & \pm 3.0 & \pm 0.9 & \pm 3.2 \\
\hline & & Experimental Values & & 6.3 & 9.1 & 4.0 & 5.9 \\
\hline
\end{tabular}

hardening plasticity model for the reinforcing steel, and nonlinear elastic constitutive relations for cracked and uncracked concrete. The test panels were modelled by 168 -node isoparametric quadrilaterals and 323 node isoparametric bar elements for the concrete and reinforcement, respectively.

Cervenka, of the Technical University in Prague, employed a relatively simple stiffness matrix approach, specially developed for the competition. The method assumes that the total material stiffness of reinforced concrete is the sum of the component stiffnesses for concrete and reinforcement. The stiffness matrix is formed and reevaluated on an iterative basis to satisfy material laws and eliminate residual stresses.

Finally, an interesting perspective is gained by studying the analytical methods used by Hillerborg in producing his comparatively good estimates. Hillerborg employed simple hand calculations involving tradi- 


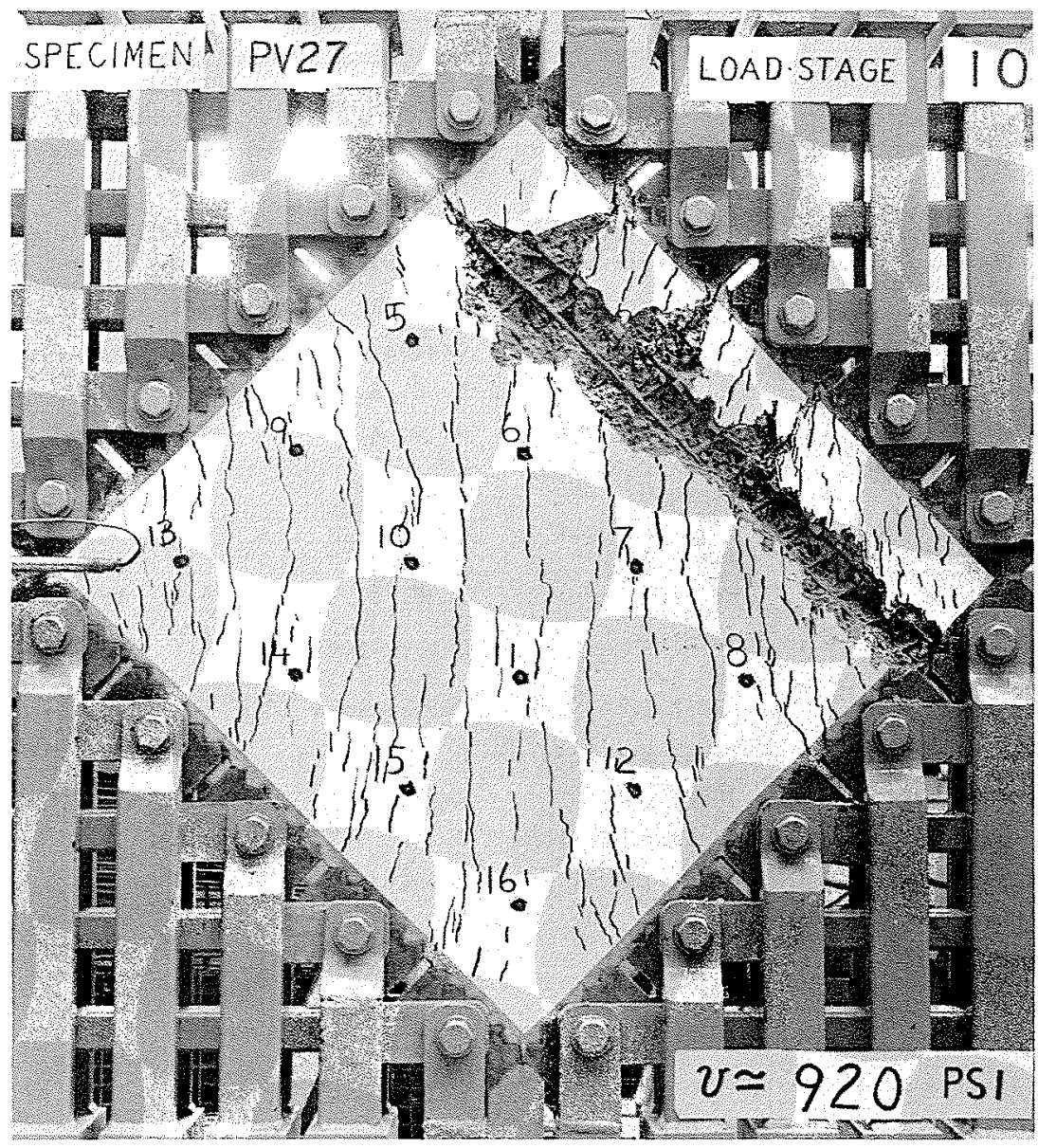

FIG. 6. Panel A after failure.

tional physical modelling techniques and basic uniaxial stress-strain relationships. He wrote: "The method I have applied is very simple and these calculations could have been made 25 years ago. 1 suppose that people using more sophisticated methods will arrive at better results, but I am very interested in finding out how great the difference in reliability is between the old, simple methods and the more sophisticated ones."

\section{The winning entry}

Dr. Vladimir Cervenka was judged winner of the competition on the basis of both ultimate stress and load-deformation predictions. His ultimate strength predictions were within $17 \%$ of the observed values for each of the four panels; no other entrant showed this consistency. Also, his load-deformation predictions closely approximated the observed response of each panel, representing well the effects of concrete tension, tension stiffening, concrete softening under biaxial stress, and reinforcement action.
For this winning effort, Dr. Červenka was awarded a Canadian Inuit soapstone carving. The presentation was made at the Comité européen du béton (CEB) Plenary Session in Munich, April 1982.

\section{Conclusions}

The results of the prediction competition serve to illustrate the following points:

I. It is unrealistic to expect great accuracy when predicting failure loads which are governed by the loadcarrying capacity of concrete. The 43 engineers involved in preparing the 27 entries for this contest were all experts in modelling reinforced concrete. Hence it might be expected that the average of 27 such estimates should be a very reliable prediction. In fact, this average prediction had an 'average error' of about $15 \%$.

2. There is no correlation between the complexity of the analytical model and the accuracy of the resulting prediction. Very simple models can produce predictions that are just as good or just as bad as those arrived 


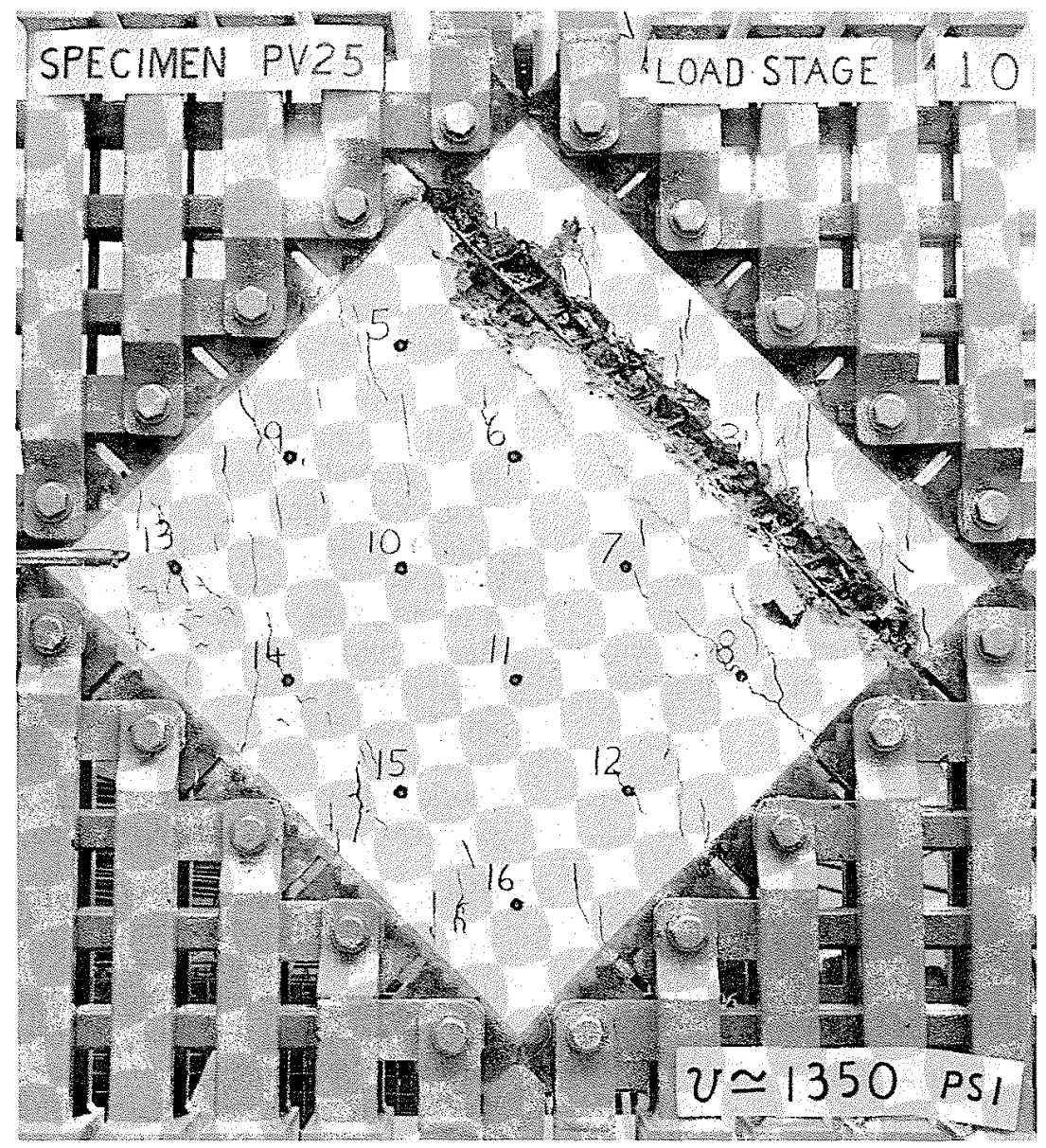

Fig. 7. Panel B after failure.

at by use of very complex models.

3. In general, current analytical models overestimate failure loads governed by failure of the concrete. Many models assume that in cracked and severely deformed reinforced concrete, the concrete can still resist compressive stresses equal to or very close to the cylinder crushing strength. Such an assumption is unconservative. In this competition the best results were achieved by a model which assumed that the compressive strength of the concrete reduced as the tensile straining transverse to the compresson increased.

4. In general, current analytical models considerably overestimate the deformations of reinforced concrete, particularly at low load levels. It seems that this is primarily caused by underestimating the influence of the tensile stresses in the concrete between the cracks.

5 . The behaviour of reinforced concrete subjected to nonproportional loading is not well understood. The ability of current analytical models to account for the influence of changing load history is very poor.
6. The many diverse analytical methods available today are very sensitive to the material properties, and modelling techniques assumed. While most of these methods can be vigorously defended on a theoretical basis, they don't always represent well actual concrete response. It remains necessary, as a general rule, to support theoretical formulations with experimental evidence.

\section{Acknowledgements}

The authors wish to express their gratitude to all the engineers who took part in preparing entries for this competition. It took time, effort, and some courage to publicly make such predictions. We hope that this effort has enabled the state-of-the-art in predicting the inplane stress response of reinforced concrete to be more clearly assessed.

The competition was conducted and the results were judged by the first two authors. The third author participated in preparing this review. 
Rüsch, H. 1960. Researches toward a general flexural theory for structural concrete. Journal of the American Concrete Institute, 57(1), pp. 1-28.

VECCHIO, F., and COLLINS, M. P. 1981. Stress-strain characteristics of reinforced concrete in pure shear. International Association for Bridge and Structural Engineering, Advanced Mechanics of Reinforced Concrete Colloquium, Delft, Final Report, pp. 211-225.

1982. The response of reinforced concrcte to inplane shear and normal stresses. Department of Civil Engineering, University of Toronto, Toronto, Ont., Publication No. $82-03,332 \mathrm{p}$

\section{Appendix 1. List of symbols}

$f_{c}^{\prime} \quad$ concrete cylinder compressive strength

$f_{y x}$ yield stress of longitudinal reinforcement

$f_{y y} \quad$ yield stress of transverse reinforcement

$\epsilon_{0} \quad$ concrete cylinder strain at peak stress

$\epsilon_{x} \quad$ strain in direction of longitudinal reinforcement

$\epsilon_{y}$ strain in direction of transverse reinforcement

$\gamma_{x y}$ shear strain

$\rho_{x}$ longitudinal reinforcement ratio

$\rho_{y} \quad$ transverse reinforcement ratio

$\sigma_{x}$ normal stress on longitudinal faces

$\sigma_{y}$ normal stress on transverse faces

$\tau$ shear stress

$\tau_{u} \quad$ ultimate shear stress

\section{Appendix 2. Summary of prediction methods}

As part of the competition, each entrant was asked to provide a brief description of the method used in formulating his predictions. The following are summaries of the descriptions submitted.

\section{Bažant and Oh (U.S.A.)}

Crack spacing was estimated, and the direction of cracks produced by the loading was determined on the basis of the principal stresses in concrete. If subsequent loading resulted in shear displacement on these cracks, the aggregate interlock resistance and the associated increase in crack opening were taken into account (Bazant and Bambarova 1980). Tension stiffening due to the tensile resistance of concrete between the cracks was also considered in an approximate way. The dowel action of the bars crossing the cracks was taken into account using the recent model of Walraven (1980), and bond behaviour was determined according to the tension-stiffening model proposed by Bazant and $\mathrm{Oh}$ (1983). The response of solid concrete between the cracks was determined on the basis of simplified, nonlinear, elastic, biaxial stress - strain relations. The stiffness of the panel was considered as the sum of the stiffness of bars and of concrete, and the deformation of concrete was taken as the sum of the deformation due to the cracks and of the deformation of the solid concrete between the cracks. All calculations were made by a computer program with step-by-step loading. (Comment made by Bazant and Oh after the results of the competition were announced: They concluded that their poor prediction for panel $\mathrm{D}$ was due to an error, namely, the use of an incorrect biaxial stress-strain relation which did not properly model the fact that the incremental stiffness relating the normal stress and strain increments parallel to the cracks significantly decreases as a result of the initial tensile cracking.)

\section{Bazzi (Switzerland)}

All calculations were performed using the computer program PIFF (Bazzi 1981), a program for incremental formulations of finite element analyses for nonlinear statics and dynamics. For the analysis, a single element was used. The element formulation was a modification of the model presented by Rossi and Bazzi (1981) at the IABSE Colloquium in Delft. The concrete was assumed to have isotropic plastic behaviour based on the Drucker-Prager yield criterion without tension. The reinforcement was modelled as having elastic-plastic behaviour according to the von Mises yield criterion with kinematic strain hardening.

\section{Blaauwendraad and Merks (Netherlands)}

The predictions were made by computer analysis, using a program that required an estimate of crack spacing. A regular pattern of parallel cracks with a constant spacing of $70 \mathrm{~mm}$ was assumed. The panels were considered as four-component structures (plain concrete, steel, bond zone, and crack zone). For plain concrete, a combination of a crushing criterion and a tension cut-off criterion was used. Steel was assumed to have ideal elastic - plastic behaviour. For bond, a stress - slip relation according to Rehm and Martin was employed, and aggregate interlock effects were predicted according to the (slightly modified) work of Reinhardt and Walraven. Dowel action of the reinforcement bars was neglected, as was shift in crack direction. (Comments by the authors: (i) The analysis procedure presupposed an assumption of the crack spacing; the results were somewhat sensitive to this; (ii) the failure criterion for a tension-compression state was not well defined; (iii) results strongly depended on the assumption of bond characteristics.)

\section{Braestrup (Denmark)}

Predictions were based on classical plasticity theory. The reinforcing bars were assumed to be rigid, perfectly plastic with the yield stress $f_{y}$, and were assumed to resist axial forces only. Compressed reinforcement was neglected. The concrete was assumed to be rigid, perfectly plastic with the square yield locus for plane stress, and the associated flow rule. The concrete compressive strength was taken to be $f_{c}^{*}=v f_{c}^{\prime}, v$ being the 


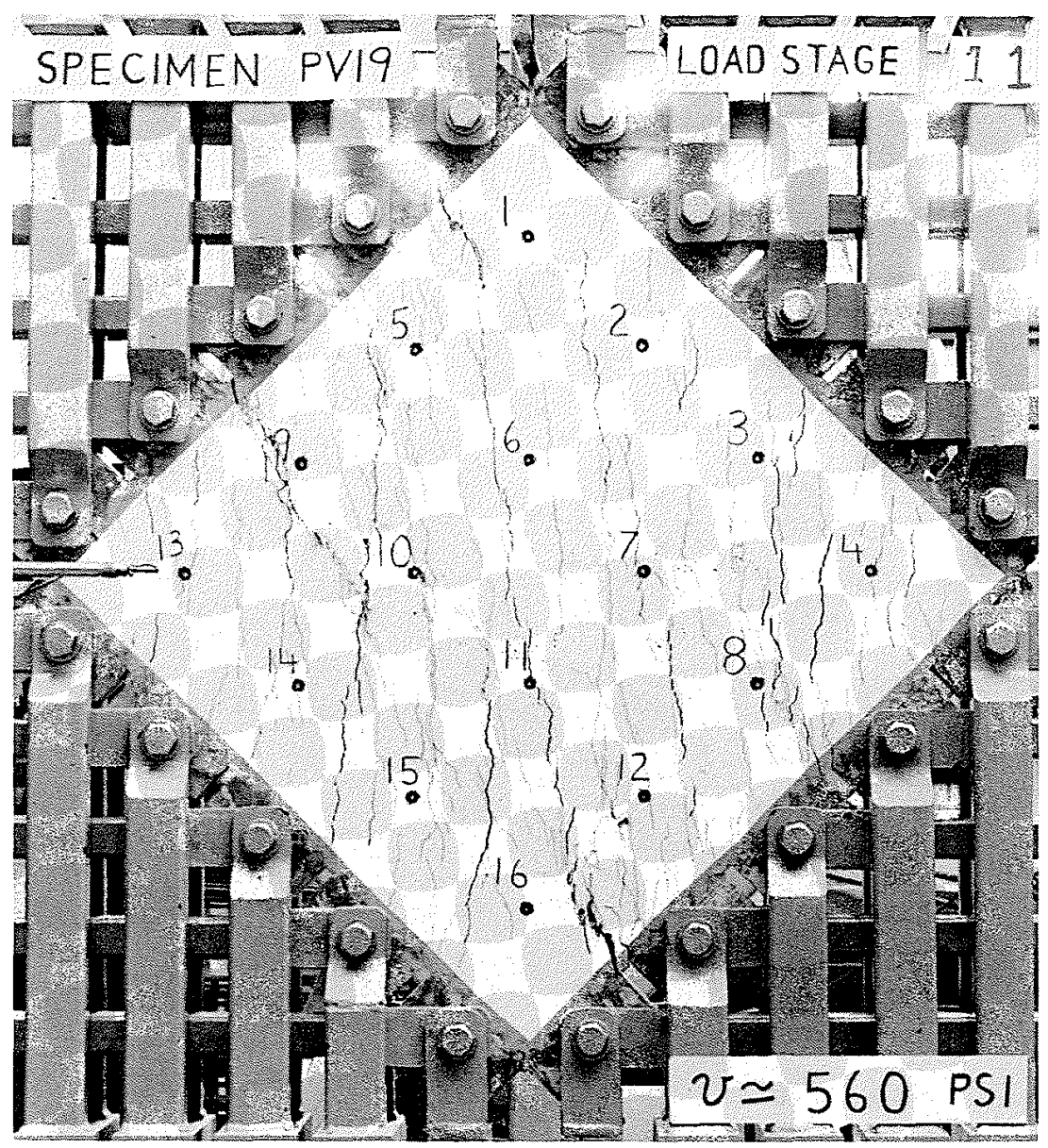

FIG. 8. Panel C after failure.

effectiveness factor estimated at 0.75 . The yield surface for orthogonally reinforced panels derived by Neilsen was used.

\section{Črvenka (Czechoslovakia)}

A summation stiffness model was used, with the total material stiffness of reinforced concrete taken as the sum of component material stiffnesses for concrete and reinforcement. Incremental solution and tangent stiffness procedures were used for determining strains corresponding to given stresses. An initial stress method was applied to satisfy material laws within stress increments. Before crack formation, the concrete was assumed isotropic. After crack formation, the axial stiffness of concrete and reinforcement and the shear stiffness of concrete between cracks was included by means of the tension-stiffening effect, and gradual reduction of concrete strength and stiffness parameters was controlled by the value of the tensile strain normal to cracks.

\section{Chang (U.S.A.)}

A finite element analysis was conducted. The nonlinear stress-strain behaviour of the concrete was represented by a plasticity model proposed by Chen and Chen (1975). The von Mises yield criterion was assumed for the reinforcing steel. For the finite element analysis, the material properties (both linear and nonlinear) of concrete and steel were smeared so that an equivalent material matrix was evaluated. A model consisting of 81 4-node plane stress elements and 100 nodes was used.

\section{Gerstle (U.S.A.)}

The solution method involved superposition of concrete and steel stiffness matrices (Cervenka and Gerstle 1971). The composite element stiffness matrix was then inverted, and multiplied by applied stresses to obtain strains. Checks were made for cracking, crushing, or yielding. Use was made of the concrete strength criterion for cracked concrete presented by Vecchio and Col- 


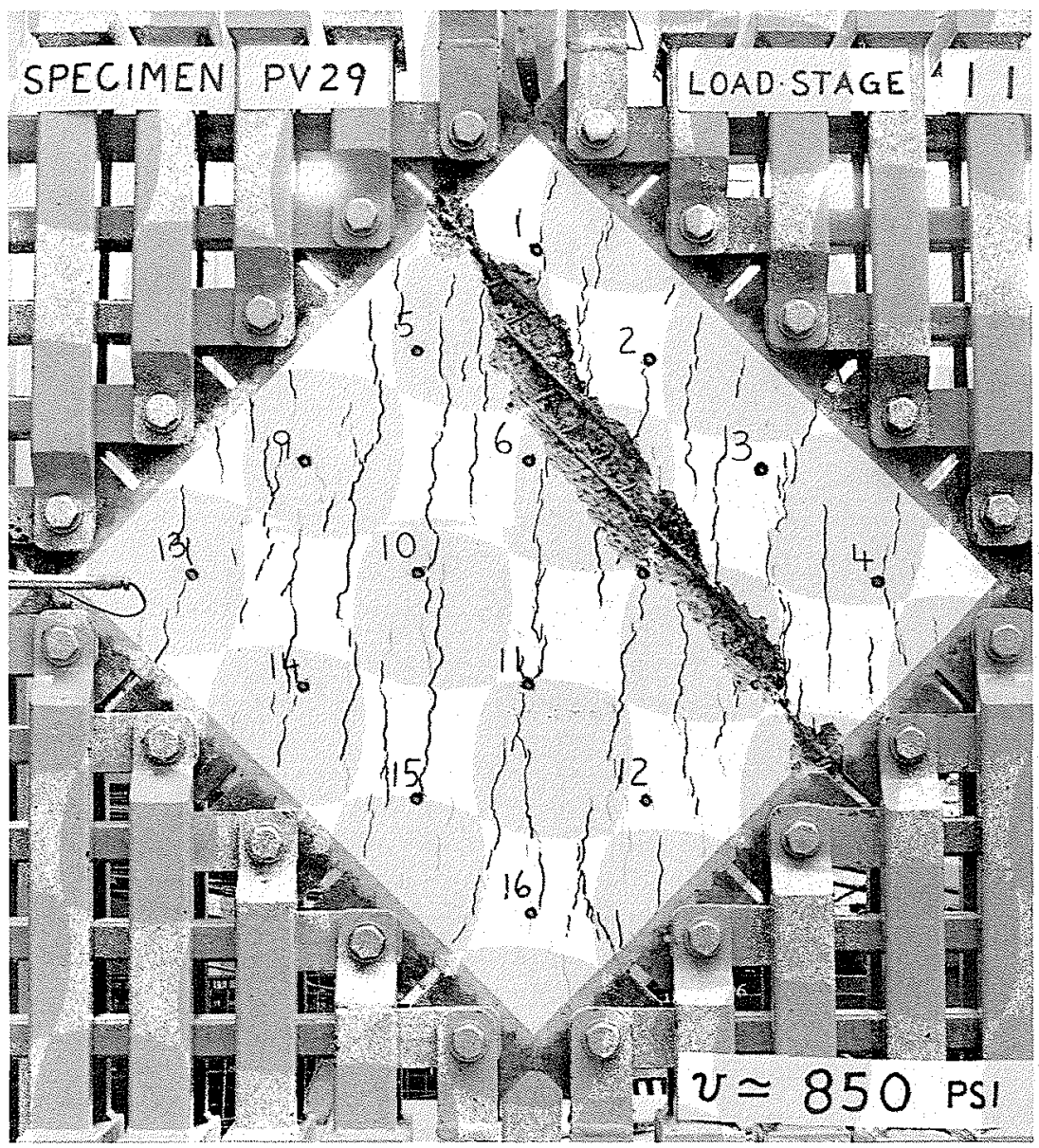

FIG. 9. Panel D after failure.

lins (1981) at Delft. Smoothing of curves was employed to account for tension stiffening and concrete nonlinearity.

\section{Gupta and Akbar (U.S.A.)}

A composite stiffness matrix approach was used (Gupta and Akbar 1981). It was assumed that the reinforcing bars were spaced sufficiently close to each other so that their effect could be accounted for by uniformly distributing the reinforcement area, so that the bond between concrete and reinforcement was perfect, so that the cracked concrete could withstand only uniaxial compressive stress parallel to the crack direction, and finally, so that the crack direction was perpendicular to the direction of the major principal strains. The nonlinear stress-strain curve for concrete under compression and transverse tension, suggested by Vecchio and Collins (1981), was used. (Comment by authors after the competition: We misanalyzed panel $\mathrm{B}$ in that we applied $\sigma_{x}$ and $\sigma_{y}$ as tensile stress, not as compressive stresses. The correct predicted shear strength is

\section{0 $\mathrm{MPa}$.}

\section{Hillerborg (Sweden)}

Before cracking, each panel was treated as a homogeneous elastic material without consideration of the reinforcement. It was assumed that cracking occurred when the first principal stress reached the tensile strength of the concrete, and that the direction of cracking was perpendicular to this stress. After cracking, it was assumed that reinforcing bars took stresses only in their own direction. The concrete was assumed to take only compressive stresses in the direction parallel to the cracks. However, when deformations were estimated, the concrete was assumed to have a reducing effect on the average strain in the reinforcement. Compatibility and equilibrium conditions were satisfied. As a concrete strength criterion, an effectiveness factor of $0.6-0.7$ was assumed.

Hilmy (U.S.A.)

Comparative study and simple equilibrium analysis 
TABLE 2. Predicted average strains $\times 10^{3}$ : PANEL A

\begin{tabular}{|c|c|c|c|c|c|c|c|c|c|c|c|c|c|}
\hline \multirow{2}{*}{$\begin{array}{l}\text { Entry } \\
\text { No. }\end{array}$} & \multirow{2}{*}{ uthors } & \multicolumn{3}{|c|}{$\tau=0.25 \tau_{u}$} & \multicolumn{3}{|c|}{$\tau=0.50 \tau_{u}$} & \multicolumn{3}{|c|}{$\tau=0.75 \tau_{u}$} & \multicolumn{3}{|c|}{$\tau=1.00 \tau_{\mathrm{u}}$} \\
\hline & & $\varepsilon_{x}$ & $\varepsilon_{y}$ & $\gamma_{x y}$ & $\varepsilon_{x}$ & $\varepsilon_{y}$ & $\gamma_{x y}$ & $\varepsilon_{x}$ & $\varepsilon_{y}$ & $\gamma_{x y}$ & $\varepsilon_{x}$ & $\varepsilon_{y}$ & $\gamma_{x y}$ \\
\hline 1 & Bažant \& Oh & 0.0 & 0.0 & 0.18 & 0.72 & 0.72 & 1.91 & 1.43 & 1.43 & 3.66 & 2.20 & 2.20 & 5.59 \\
\hline 2 & Bazz1 & 0.5 & 0.5 & 1.4 & 1.0 & 1.0 & 2.8 & 1.6 & 1.6 & 4.3 & 2.1 & 2.1 & 5.7 \\
\hline 3 & $\begin{array}{l}\text { Blaauwendraad } \\
\& \text { Merks }\end{array}$ & 0.0 & 0.0 & 0.12 & 0.30 & 0.30 & 1.06 & 0.49 & 0.49 & 1.77 & 0.60 & 0.60 & 2.70 \\
\hline 4 & Braestrup & - & - & - & - & - & - & - & - & - & - & - & - \\
\hline 5 & Cervenka & 0.04 & 0.04 & 0.27 & 0.65 & 0.65 & 1.86 & 1.14 & 1.14 & 3.29 & 1.65 & 1.65 & 5.44 \\
\hline 6 & Chang & 0.50 & 0.50 & 1.41 & 1.01 & 1.01 & 2.75 & 1.52 & 1.51 & 4.18 & 2.10 & 2.10 & 5.80 \\
\hline 7 & Gerstle & 0.0 & 0.0 & 0.2 & 0.9 & 0.9 & 2.5 & 1.5 & 1.5 & 4.0 & 2.5 & 2.5 & 6.0 \\
\hline 8 & Gupta \& Akbar & 0.33 & 0.33 & 0.90 & 0.65 & 0.65 & 1.85 & 0.98 & 0.98 & 2.92 & 1.30 & 1.30 & 4.48 \\
\hline 9 & Hillerborg & 0.0 & 0.0 & 0.2 & 0.8 & 0.8 & 2.2 & 1.5 & 1.5 & 3.8 & 2.0 & 2.0 & 6.0 \\
\hline 10 & Hilmy & - & - & 1.0 & - & - & 2.0 & - & - & 4.0 & - & - & 9.0 \\
\hline 11 & $\begin{array}{l}\text { Kamer] } \\
\text { et al. }\end{array}$ & 0.16 & 0.16 & 0.65 & 0.80 & 0.80 & 2.46 & 1.45 & 1.45 & 4.28 & 2.1 & 2.1 & 6.1 \\
\hline 12 & $\begin{array}{l}\text { Kanellopoulos } \\
\text { et al. }\end{array}$ & - & - & - & - & - & - & - & - & - & - & - & - \\
\hline 13 & Klein & 0.56 & 0.56 & 1.50 & 1.10 & 1.10 & 3.05 & 1.61 & 1.61 & 4.60 & 2.31 & 2.31 & 6.80 \\
\hline 14 & $\begin{array}{l}\text { Kolmar \& } \\
\text { Meh1horn }\end{array}$ & 0.28 & 0.28 & 0.70 & 0.97 & 0.97 & 2.65 & 1.59 & 1.59 & 4.55 & 2.22 & 2.22 & 6.70 \\
\hline 15 & os 8 & - & - & - & - & - & - & - & - & - & - & - & - \\
\hline 16 & $\begin{array}{l}\text { Maekawa } \& \\
\text { Okamura }\end{array}$ & 0.0 & 0.0 & 0.17 & 0.55 & 0.55 & 1.90 & 0.78 & 0.78 & 2.99 & 1.05 & 1.05 & 4.79 \\
\hline 17 & Noguchi et al. & 0.35 & 0.35 & 0.81 & 0.58 & 0.58 & 1.85 & 0.88 & 0.88 & 2.90 & 1.36 & 1.36 & 4.00 \\
\hline 18 & Olseñ & 0.4 & 0.4 & $1: 1$ & 1.0 & 1.0 & 2.8 & 1.5 & 1.5 & 4.1 & 2.1 & 2.1 & 6.1 \\
\hline 19 & Pajari & 0.0 & 0.0 & 0.16 & 0.94 & 0.94 & 2.67 & 1.52 & 1.52 & 4.38 & 2.32 & 2.32 & 6.43 \\
\hline 20 & $\begin{array}{l}\text { Razaqpur \& } \\
\text { Ghali. }\end{array}$ & 0.28 & 0.28 & 0.85 & 1.00 & 1.00 & 2.90 & 1.46 & 1.46 & 4.85 & 1.82 & 1.82 & 7.73 \\
\hline 21 & Rein & - & - & - & - & - & - & - & - & - & . & - & - \\
\hline 22 & Schäfer & - & - & - & - & - & - & - & - & - & - & - & - \\
\hline 23 & $\begin{array}{l}\text { Schmidt-Gönner } \\
\& \text { Mehlhorn }\end{array}$ & 0.5 & 0.5 & 1.3 & 1.2 & 1.2 & 3.5 & 1.7 & 1.7 & 5.4 & 2.2 & 2.2 & 8.2 \\
\hline 24 & Shirai & 0.18 & 0.18 & 0.81 & 0.84 & 0.84 & 3.22 & 1.70 & 1.70 & 6.23 & 2.39 & 2.39 & 10.17 \\
\hline 25 & $\begin{array}{l}\text { Walraven \& } \\
\text { Reinhardt }\end{array}$ & - & - & - & - & - & - & - & - & - & - & - & - \\
\hline 26 & Walter \& Mang & 0.50 & 0.50 & 1.4 & 1.1 & 1.1 & 2.9 & 1.65 & 1.65 & 4.6 & 5.0 & 5.0 & 12.0 \\
\hline 27 & Weischede & - & - & - & - & - & - & - & - & - & - & - & - \\
\hline Low & Value & 0.00 & 0.00 & 0.12 & 0.30 & 0.30 & 1.06 & 0.49 & 0.49 & 1.77 & 0.60 & 0.60 & 2.70 \\
\hline High & Value & 0.56 & 0.56 & 1.50 & 1.20 & 1.20 & 3.50 & 1.70 & 1.70 & 6.23 & 5.00 & 5.00 & 12.00 \\
\hline Mean & & 0.24 & 0.24 & 0.76 & 0.85 & $0.8 j$ & 2.44 & 1.37 & 1.37 & 4.04 & 2.07 & 2.07 & 6.49 \\
\hline Stanc & dard Deviation & 0.21 & 0.21 & 0.49 & 0.23 & 0.23 & 0.60 & 0.34 & 0.34 & 0.97 & 0.87 & 0.87 & 2.13 \\
\hline Exper & rimental Value & 0.00 & 0.03 & 0.17 & 0.18 & 0.25 & 0.86 & 0.64 & 0.71 & 2.46 & 1.15 & 1.17 & 4.54 \\
\hline
\end{tabular}

were used.

Kamerling, Vlugt, Fijneman and Mier (Netherlands) No description was provided.

Kanellopoulos, Marti, and Thürlimann (Switzerland)

Predictions were based on yield conditions for reinforced concrete wall elements according to the theory of plasticity. The effective concrete strength was considered as a function of the strain conditions in the cracked panel.

\section{Klein (U.S.A.)}

A finite element analysis was performed using triangular, isoparametric, quadratic elements (plane stress 
TABLE 3. Predicted average strains $\times 10^{3}$ : PANEL B

\begin{tabular}{|c|c|c|c|c|c|c|c|c|c|c|c|c|c|}
\hline \multirow{2}{*}{$\begin{array}{l}\text { Entry } \\
\text { No. }\end{array}$} & \multirow{2}{*}{ uthors } & \multicolumn{3}{|c|}{$\tau=0.25 \tau_{u}$} & \multicolumn{3}{|c|}{$\tau=0.50 \tau_{u}$} & \multicolumn{3}{|c|}{$\tau=0.75 \tau_{u}$} & \multicolumn{3}{|c|}{$\tau=1.00 \tau_{u}$} \\
\hline & & $\varepsilon_{x}$ & $\varepsilon_{y}$ & $\gamma_{x y}$ & $\varepsilon_{x}$ & $\varepsilon_{\mathrm{y}}$ & $\gamma_{x y}$ & $\varepsilon_{\mathrm{x}}$ & $\varepsilon_{y}$ & $\gamma_{x y}$ & $E_{x}$ & $\varepsilon_{y}$ & $\gamma_{x y}$ \\
\hline 1 & Bažant \& Oh & -0.07 & -0.07 & 0.30 & 0.15 & 0.15 & 1.21 & 0.51 & 0.51 & 2.66 & 0.86 & 0.86 & 5.70 \\
\hline 2 & Bazz1 & 0.2 & 0.2 & 0.9 & 0.4 & 0.4 & 1.75 & 0.6 & 0.6 & 2.6 & 0.8 & 0.8 & 3.5 \\
\hline 3 & $\begin{array}{l}\text { Blaauwendraad } \\
\& \text { Merks }\end{array}$ & -0.05 & -0.05 & 0.14 & -0.13 & -0.13 & 0.33 & -0.06 & -0.06 & 0.94 & -0.19 & -0.19 & 1.63 \\
\hline 4 & Braestrup & - & - & - & - & - & - & - & - & - & - & - & - \\
\hline 5 & Cervenka & -0.05 & -0.05 & 0.21 & 0.04 & 0.04 & 0.80 & 0.29 & 0.29 & 1.87 & 0.52 & 0.52 & 3.63 \\
\hline 6 & Chang & -0.05 & -0.05 & 0.27 & 0.36 & 0.36 & 1.00 & 0.55 & 0.55 & 2.59 & 0.74 & 0.74 & 3.68 \\
\hline 7 & Gerstle & -0.1 & -0.1 & 0.3 & -0.2 & -0.2 & 0.6 & 0.6 & 0.6 & 2.0 & 1.0 & 1.0 & 3.6 \\
\hline 8 & Gupta \& Akbar & 0.44 & 0.44 & 1.09 & 0.89 & 0.89 & 2.23 & 1.33 & 1.33 & 3.48 & 1.78 & 1.78 & 5.32 \\
\hline 9 & Hillerborg & -0.05 & -0.05 & 0.2 & -0.1 & -0.1 & 0.4 & -0.15 & -0.15 & 0.6 & 0.5 & 0.5 & 3.5 \\
\hline 10 & Hilmy & - & - & 0.2 & - & - & 0.4 & - & - & 0.8 & - & - & 8.0 \\
\hline 11 & $\begin{array}{l}\text { Kame } \\
\text { et a }\end{array}$ & -0.08 & -0.08 & 0.50 & 0.11 & 0.11 & 2.58 & 0.41 & 0.41 & 5.30 & 0.71 & 0.71 & 8.00 \\
\hline 12 & & - & - & - & - & - & - & - & - & - & - & - & - \\
\hline 13 & Klein & 0.04 & 0.04 & 0.26 & 0.36 & 0.36 & 1.70 & 0.51 & 0.51 & 2.80 & 0.61 & 0.61 & 4.60 \\
\hline 14 & $\begin{array}{l}\text { Kol } \\
\text { Meh }\end{array}$ & -0.05 & -0.05 & 0.25 & 0.18 & 0.18 & 1.35 & 0.41 & 0.41 & 2.40 & 0.63 & 0.63 & 3.35 \\
\hline 15 & os \& & - & - & - & - & - & - & - & - & - & - & - & - \\
\hline 16 & $\begin{array}{l}\text { Maeka } \\
\text { Okamu }\end{array}$ & 0.04 & 0.04 & 0.20 & 0.08 & 0.08 & 0.42 & 0.28 & 0.28 & 1.07 & 0.43 & 0.43 & 3.17 \\
\hline 17 & Noguchi et al. & 0.48 & -0.33 & 0.86 & 1.10 & $-1) .58$ & 2.23 & 1.80 & -1.00 & 3.58 & 2.81 & -1.78 & 5.78 \\
\hline 18 & O1sen & -0.03 & -0.03 & 0.12 & -0.06 & -0.06 & 0.25 & 0.22 & 0.22 & 1.7 & 0.4 & 0.4 & 2.1 \\
\hline 19 & Pajar & -0.04 & -0.04 & 0.16 & -0.09 & -0.09 & 0.32 & 0.03 & 0.03 & 1.18 & 0.58 & 0.58 & 3.44 \\
\hline 20 & pur \& & -0.29 & -0.27 & 0.20 & 0.16 & 0.20 & 1.42 & 0.35 & 0.37 & 3.35 & 0.40 & 0.51 & 4.55 \\
\hline 21 & Reineck & - & - & - & - & - & - & - & - & - & - & - & - \\
\hline 22 & Schäfer & - & - & - & - & - & - & - & - & - & - & - & - \\
\hline 23 & $\begin{array}{l}\text { Schmidt-Gönner } \\
\& \text { Mehlhorn }\end{array}$ & -0.3 & 0.02 & 0.07 & -0.5 & 0.3 & 0.4 & 0.3 & 0.8 & 2.6 & 0.80 & 0.85 & 5.0 \\
\hline 24 & Shirai & -0.06 & -0.06 & 0.24 & 0.08 & 0.08 & 1.10 & 0.07 & 0.07 & 1.58 & 0.22 & 0.22 & 4.48 \\
\hline 25 & $\begin{array}{l}\text { Wair } \\
\text { Rein }\end{array}$ & - & - & - & - & - & - & - & - & - & - & - & - \\
\hline 26 & Walter \& Mang & -0.06 & -0.06 & 0.27 & 0.30 & 0.30 & 1.5 & 0.49 & 0.49 & 2.6 & 0.69 & 0.69 & 4.6 \\
\hline 27 & Weischede & - & - & - & - & - & - & - & - & - & - & - & - \\
\hline Low V & क्षा & -0.30 & -0.33 & 0.07 & -0.50 & -0.58 & 0.25 & -0.15 & -1.00 & 0.60 & -0.19 & -1.78 & 1.63 \\
\hline High & Value & 0.48 & 0.44 & 1.09 & 1.10 & 0.89 & 2.58 & 1.80 & 1.33 & 5.30 & 2.81 & 1.78 & 8.00 \\
\hline Mean & & 0.00 & -0.03 & 0.34 & 0.16 & 0.12 & 1.10 & 0.45 & 0.33 & 2.28 & 0.75 & 0.52 & 4.23 \\
\hline Stand & dard Deviation & 0.20 & 0.16 & 0.28 & 0.36 & 0.30 & 0.73 & 0.46 & 0.46 & 1.14 & 0.62 & 0.67 & 1.86 \\
\hline Exper & rimental Value & -0.07 & -0.03 & 0.19 & -0.06 & -0.04 & 0.60 & 0.03 & 0.08 & 1.60 & 0.31 & 0.39 & 5.51 \\
\hline
\end{tabular}

state). A nonlinear, elastic, biaxial, stress-strain relation for concrete (Link 1976) was used together with a failure criterion based on Kupfer's tests (1969). Cracks were considered smeared over the panel area, and normal to the principal tensile stress. Full shear transfer was assumed across cracks. The reinforcement was modelled as a smeared layer, with perfect bond and elastic-plastic behaviour. Tension-stiffening effects and dowel action were not considered.

\section{Kolmar and Mehlhorn (Germany)}

A finite element analysis was performed using triangular, linear strain elements (plane stress state). The biaxial nonlinear stress-strain relations of Kupfer and 
TABLE 4. Predicted average strains $\times 10^{3}$ : PANEL $C$

\begin{tabular}{|c|c|c|c|c|c|c|c|c|c|c|c|c|c|}
\hline \multirow{2}{*}{$\begin{array}{l}\text { Entry } \\
\text { No. }\end{array}$} & \multirow{2}{*}{ ithors } & \multicolumn{3}{|c|}{$\tau=0.25 \tau_{u}$} & \multicolumn{3}{|c|}{$\tau=0.50 \tau_{u}$} & \multicolumn{3}{|c|}{$\tau=0.75 \tau_{u}$} & \multicolumn{3}{|c|}{$\tau=1.00 \tau_{u}$} \\
\hline & & $\varepsilon_{x}$ & $\varepsilon_{y}$ & $\gamma_{x y}$ & $\varepsilon_{\mathrm{x}}$ & $\varepsilon_{y}$ & $\gamma_{x y}$ & $\varepsilon_{x}$ & $\varepsilon_{y}$ & $\gamma_{x y}$ & $\varepsilon_{x}$ & $E_{y}$ & $\gamma_{x y}$ \\
\hline 1 & Bažant \& Oh & 0.0 & 0.0 & 0.11 & 0.29 & 0.38 & 0.93 & 0.85 & 1.31 & 2.64 & 2.02 & 10.82 & 13.56 \\
\hline 2 & Bazz1 & 0.3 & 0.5 & 1.1 & 0.7 & 1.1 & 2.3 & 1.2 & 2.3 & 4.2 & 2.2 & 5.7 & 8.2 \\
\hline 3 & $\begin{array}{l}\text { Blaaur } \\
\text { \& Merk }\end{array}$ & 0.0 & 0.0 & 0.13 & 0.32 & 0.63 & 1.40 & 0.53 & 1.12 & 2.41 & 0.87 & 2.40 & 4.40 \\
\hline 4 & Braestrup & - & - & - & - & - & - & - & - & - & - & - & - \\
\hline 5 & Cervenka & 0.0 & 0.0 & 0.10 & 0.07 & 0.09 & 0.39 & 0.64 & 0.90 & 2.07 & 1.02 & 1.86 & 3.69 \\
\hline 6 & Chang & 0.0 & 0.0 & 0.12 & 0.76 & 0.60 & 1.80 & 1.00 & 0.99 & 2.63 & 1.33 & 1.45 & 3.39 \\
\hline 7 & Gerstle & 0.0 & 0.0 & 0.1 & 0.0 & 0.0 & 0.15 & 0.0 & 0.0 & 0.2 & 0.6 & 1.5 & 2.6 \\
\hline 8 & Gupta \& Akbar & 0.26 & 0.43 & 0.87 & 0.52 & 0.87 & 1.77 & 0.77 & 1.31 & 2.73 & 1.24 & 3.58 & 5.92 \\
\hline 9 & H11lerborg & 0.0 & 0.0 & 0.1 & 0.1 & 0.2 & 0.8 & 1.0 & 1.5 & 3.5 & 2.0 & 4.0 & 7.5 \\
\hline 10 & H1lmy & - & - & 0.7 & - & - & 1.5 & - & - & 3.0 & - & - & 6.0 \\
\hline 11 & $\begin{array}{l}\text { Kame } \\
\text { et a }\end{array}$ & 0.0 & 0.0 & 0.17 & 0.51 & 0.47 & 1.39 & 1.34 & 1.23 & 3.26 & 2.18 & 2.00 & 5.25 \\
\hline 12 & k & - & - & - & - & - & - & - & - & - & - & - & - \\
\hline 13 & Kleln & 0.0 & 0.0 & 0,20 & 0.83 & 0.91 & 2.00 & 1.31 & 1.47 & 3.50 & 2.11 & 2.38 & 5.70 \\
\hline 14 & $\begin{array}{l}\text { Kolmar \& } \\
\text { Mehlhorn }\end{array}$ & 0.0 & 0.0 & 0.15 & 0.59 & 0.70 & 1.65 & 1.33 & 1.50 & 3.80 & 2.10 & 2.31 & 5.50 \\
\hline 15 & os 8 & - & - & - & - & - & - & - & - & - & - & - & - \\
\hline 16 & $\begin{array}{l}\text { Maekawa \& } \\
\text { Okamura }\end{array}$ & 0.0 & 0.0 & 0.12 & 0.36 & 0.95 & 1.34 & 0.67 & 1.24 & 2.63 & 1.35 & 5.11 & 7.25 \\
\hline 17 & Noguch1 et al. & 0.0 & 0.0 & 0.10 & 0.36 & -0.08 & 0.44 & 0.49 & 0.29 & 1.13 & 0.77 & 1.11 & 2.48 \\
\hline 18 & 0lsen & 0.0 & 0.0 & 0.08 & 0.71 & 0.71 & 1.9 & 1.14 & 1.14 & 3.1 & 2.15 & 8.0 & 11.6 \\
\hline 19 & Pajar1 & 0.0 & 0.0 & 0.12 & 0.25 & 0.43 & 2.10 & 1.45 & 2.44 & 4.66 & 2.44 & 4.88 & 9.58 \\
\hline 20 & $\begin{array}{l}\text { Razaqpur \& } \\
\text { Ghal1 }\end{array}$ & 0.25 & 0.42 & 1.54 & 0.92 & 1.57 & 3.21 & 1.68 & 3.80 & 6.85 & 2.26 & 5.54 & 10.06 \\
\hline 21 & Reineck & - & - & - & - & - & - & - & - & - & - & - & - \\
\hline 22 & Schäfer & - & - & - & - & - & - & - & - & - & - & - & - \\
\hline 23 & $\begin{array}{l}\text { Schmldt-Gönner } \\
\& \text { Mehlhorn }\end{array}$ & 0.0 & 0.0 & 0.15 & 1.0 & 1.8 & 3.5 & 1.8 & 4.5 & 7.3 & 2.3 & 9.5 & 12.2 \\
\hline 24 & Sh1rai & 0.12 & 0.19 & 0.60 & 0.24 & 1.28 & 2.67 & 0.47 & 2.36 & 4.60 & 1.30 & 4.19 & 8.35 \\
\hline 25 & $\begin{array}{l}\text { Walra } \\
\text { Re1nh }\end{array}$ & - & - & - & - & - & - & - & - & - & - & - & - \\
\hline 26 & Walter \& Mang & 0.0 & 0.0 & 0.08 & 0.0 & 0.0 & 0.18 & 0.48 & 1.3 & 2.1 & 0.7 & 3.0 & 4.0 \\
\hline 27 & Weischede & - & - & - & - & - & - & - & - & - & - & - & - \\
\hline Low & Value & 0.00 & 0.00 & 0.08 & 0.00 & -0.08 & 0.15 & 0.00 & 0.00 & 0.20 & 0.60 & 1.11 & 2.48 \\
\hline High & Value & 0.30 & 0.43 & 1.54 & 1.00 & 1.57 & 3.50 & 1.80 & 4.50 & 7.30 & 2.44 & 10.82 & 13.56 \\
\hline Mean & & 0.05 & 0.08 & 0.33 & 0.45 & 0.66 & 1.57 & 0.96 & 1.62 & 3.32 & 1.63 & 4.18 & 6.86 \\
\hline Stanc & dard Deviation & 0.10 & 0.17 & 0.41 & 0.31 & 0.53 & 0.93 & 0.47 & 1.08 & 1.67 & 0.63 & 2.77 & 3.24 \\
\hline Exper & rimental Value & -0.01 & 0.04 & 0.05 & 0.07 & 0.16 & 0.36 & 0.45 & 0.91 & 1.78 & 1.15 & 8.63 & 10.51 \\
\hline
\end{tabular}

Gerstle (1973) and the failure criterion formulations of Kupfer et al. (1969) were used to model concrete behaviour. For reinforcement, elastic-plastic behaviour without strain hardening was assumed. The smeared crack approach was adopted. Direction of primary cracks was taken normal to the main tensile stress, and full shear transfer across cracks was assumed with no reduction of shear stiffness. The analysis involved su- perposition of concrete and steel stiffness matrices. Dowel action of reinforcement was neglected, as was reduced concrete thickness and strength, owing to notch effect of reinforcement.

\section{Kotsovos and Bedard (United Kingdom)}

Analysis was carried out using a linear finite element program incorporated into an iterative procedure. 
TABLE 5. Predicted average strains $\times 10^{3}$ : PANEL $D$

\begin{tabular}{|c|c|c|c|c|c|c|c|c|c|c|c|c|c|}
\hline \multirow{2}{*}{$\begin{array}{l}\text { Entry } \\
\text { No. }\end{array}$} & \multirow[b]{2}{*}{ Authors } & \multicolumn{3}{|c|}{$\tau=0.25 \tau_{u}$} & \multicolumn{3}{|c|}{$\mathrm{r}=0.50 \tau_{\mathrm{u}}$} & \multicolumn{3}{|c|}{$\tau=0.75 \tau_{u}$} & \multicolumn{3}{|c|}{$\tau=1.00 \bar{i}_{\mathrm{u}}$} \\
\hline & & $\varepsilon_{\mathrm{x}}$ & $\varepsilon_{\mathrm{y}}$ & $Y_{x y}$ & $\varepsilon_{\mathrm{x}}$ & $\varepsilon_{\mathrm{y}}$ & $\gamma_{x y}$ & $\varepsilon_{x}$ & $\varepsilon_{y}$ & $Y_{x y}$ & $E_{x}$ & $\varepsilon_{\mathrm{y}}$ & $\gamma_{x y}$ \\
\hline 1 & Bažant \& Oh & 0.68 & 0.94 & 2.01 & 1.67 & 5.06 & 7.79 & 1.66 & 5.13 & 8.48 & 1.64 & 5.41 & 11.18 \\
\hline 2 & Bazz1 & 0.8 & 1.2 & 2.5 & 1.3 & 2.2 & 4.4 & 1.3 & 2.2 & 4.7 & 1.3 & 2.2 & 5.3 \\
\hline 3 & $\begin{array}{l}\text { Blaauwendraad } \\
\& \text { Merks }\end{array}$ & 0.0 & 0.0 & 0.10 & 0.33 & 0.58 & 1.26 & 0.53 & 0.93 & 2.05 & 0.68 & 1.67 & 4.00 \\
\hline 4 & Braestrup & - & - & - & - & - & - & - & - & - & - & - & - \\
\hline 5 & Cervenka & 0.0 & 0.0 & 0.13 & 0.72 & 0.91 & 2.08 & 1.11 & 1.52 & 3.43 & 1.18 & 2.08 & 4.53 \\
\hline 6 & Chang & 0.75 & 0.87 & 2.07 & 1.21 & 1.41 & 3.50 & 1.21 & 1.41 & 3.98 & 1.21 & 1.41 & 4.48 \\
\hline 7 & Gerstle & 0.6 & 1.2 & 2.0 & 1.1 & 2.2 & 3.7 & 1.1 & 2.2 & 4.3 & 1.1 & 2.2 & 4.7 \\
\hline 8 & Gupta \& Akbar & 0.30 & 0.43 & 0.89 & 0.59 & 0.88 & 1.82 & 0.89 & 1.32 & 2.81 & 1.32 & 2.73 & 5.21 \\
\hline 9 & Hillerborg & 0.0 & 0.0 & 0.2 & 1.0 & 1.3 & 2.7 & 1.5 & 1.8 & 4.2 & 1.7 & 1.6 & 5.5 \\
\hline 10 & Hilmy & - & - & 0.6 & - & - & 1.2 & - & - & 3.0 & - & - & 9.0 \\
\hline 11 & $\begin{array}{l}\text { Kamer } \\
\text { et al }\end{array}$ & 1.7 & 1.3 & 3.6 & 1.4 & 1.0 & 4.5 & 1.1 & 0.7 & 5.5 & 1.0 & 0.5 & 6.5 \\
\hline 12 & $\begin{array}{l}\text { Kanellopoulos } \\
\text { et al. }\end{array}$ & - & - & - & - & - & - & - & - & - & - & - & - \\
\hline 13 & Klein & 0.67 & 0.79 & 1.75 & 1.05 & 1.12 & 3.00 & 1.02 & 1.07 & 3.90 & 0.91 & 0.95 & 5.05 \\
\hline 14 & $\begin{array}{l}\text { Kolm } \\
\text { Mehl }\end{array}$ & 0.70 & 0.78 & 1.80 & 1.23 & 1.34 & 3.70 & 1.24 & 1.33 & 4.95 & 1.50 & 1.05 & 6.90 \\
\hline 15 & $\cos \&$ & - & - & - & - & - & - & - & - & - & - & - & - \\
\hline 16 & $\begin{array}{l}\text { Maekawa \& } \\
\text { Okamura }\end{array}$ & 0.0 & 0.0 & 0.16 & 0.60 & 1.02 & 2.35 & 1.05 & 2.23 & 4.69 & 1.08 & 2.45 & 6.41 \\
\hline 17 & Noguchi et al. & 0.70 & 0.95 & 2.25 & 1.50 & 0.31 & 3.10 & 2.40 & -0.85 & 3.96 & 3.15 & -1.51 & 6.07 \\
\hline 18 & Olsen & 0.4 & 0.5 & 1.1 & 1.2 & 1.5 & 3.7 & 1.2 & 1.5 & 4.5 & 1.2 & 1.5 & 5.5 \\
\hline 19 & Pajari & 0.06 & 0.07 & 0.30 & 0.96 & 1.21 & 2.11 & 1.26 & 2.00 & 4.63 & 1.25 & 2.00 & 5.30 \\
\hline 20 & $\begin{array}{l}\text { Raza } \\
\text { Ghal }\end{array}$ & 0.0 & 0.0 & 0.16 & 1.16 & 1.81 & 3.85 & 1.37 & 2.44 & 5.35 & 1.42 & 2.72 & 7.71 \\
\hline 21 & Rei & - & - & - & - & - & - & - & - & - & - & - & - \\
\hline 22 & & - & - & - & - & - & - & - & - & - & - & - & - \\
\hline 23 & $\begin{array}{l}\text { Schmidt-Gönner } \\
\& \text { Mehlhorn }\end{array}$ & 0.2 & 0.5 & 0.8 & 1.4 & 2.6 & 4.8 & 1.8 & 5.7 & 9.0 & 2.2 & 8.2 & 13.0 \\
\hline 24 & Shirai & 0.13 & 0.15 & 0.55 & 0.19 & 1.06 & 2.25 & 0.29 & 1.66 & 3.37 & 0.74 & 3.21 & 7.49 \\
\hline 25 & $\begin{array}{l}\text { Walra } \\
\text { Reinh }\end{array}$ & - & - & - & - & - & - & - & - & - & - & - & - \\
\hline 26 & Walcer \& Mang & 0.0 & 0.0 & 0.08 & 0.41 & 0.84 & 1.5 & 0.63 & 2.3 & 2.4 & 0.96 & 1.6 & 3.2 \\
\hline 27 & Weischede & - & - & - & - & - & - & - & - & - & - & - & - \\
\hline Low $V$ & Value & 0.00 & 0.00 & 0.08 & 0.19 & 0.31 & 1.20 & 0.29 & -0.85 & 2.05 & 0.68 & -1.51 & 3.20 \\
\hline High & Value & 1.70 & 1.30 & 3.60 & 1.67 & 5.06 & 7.79 & 2.40 & 5.70 & 9.00 & 3.15 & 8.20 & 13.00 \\
\hline Mean & & 0.40 & 0.51 & 1.15 & 1.00 & 1.49 & 3.17 & 1.19 & 1.87 & 4.46 & 1.34 & 2.21 & 6.35 \\
\hline Stand & dard Deviation & 0.44 & 0.48 & 1.02 & 0.42 & 1.04 & 1.54 & 0.47 & 1.45 & 1.73 & 0.56 & 1.97 & 2.40 \\
\hline Exper & rimental Value & -0.01 & -0.03 & 0.14 & 0.42 & 0.52 & 1.48 & 0.86 & 2.26 & 4.47 & 0.85 & 2.92 & 6.12 \\
\hline
\end{tabular}

Eight-node plane isoparametric elements and threenode linear isoparametric elements were used to simulate concrete and steel, respectively. Concrete stressstrain relations were based on a mathematical model of deformational behaviour under generalized stresses (Kotsovos 1980). When ultimate strength was exceeded, a crack was assumed to occur in the direction of the maximum principal compressive stress in compliance with fracture mechanisms of concrete. Perfect bond was assumed.

Maekawa and Okamura (Japan)

Predictions were obtained by implementation of the nonlinear finite element method developed by NAPRA 


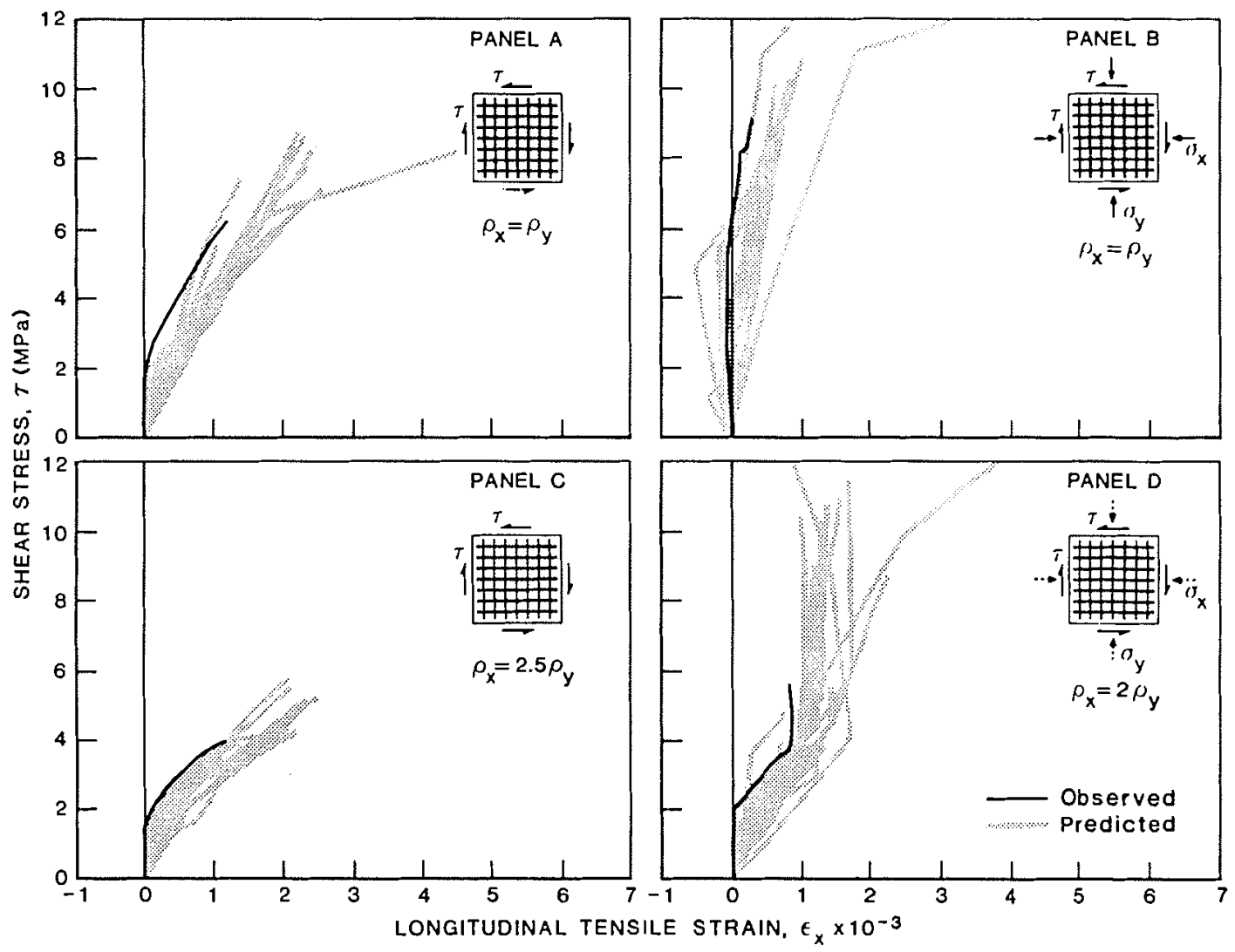

FiG. 10. Scatter in predicted longitudinal strains $\left(\epsilon_{r}\right)$.

(Nonlinear Analysis Program Research Association, University of Tokyo). One-dimensional three-node isoparametric elements and two-dimensional eight-node isoparametric elements were used for modelling of reinforcing bars and concrete, respectively. Each panel was divided into 16 concrete elements and 32 steel elements. The kinematic strain-hardening plasticity model was used for reinforcing bars, and nonlinear elastic constitutive relations were used for uncracked (Niwa et al. 1981) and cracked (Maekawa 1982) concrete. Crack orientation was considered to be normal to the major principal stress, and the stress component normal to a crack was reduced to zero. When the strain normal to the crack was compressive, the crack was closed and the condition assumed to be the same as that of uncracked concrete. If concrete had experienced previous cracking, the stress component normal to a crack was calculated and the crack was assumed to reopen as soon as the stress became tensile.

\section{Noguchi, Naganuma, and Hagiwara (Japan)}

The nonlinear behaviour of the panels was predicted using the finite element method. Concrete was represented by a linear strain triangular element with six nodal points. Longitudinal and transverse reinforcing bars were represented by bar elements. Stress-strain relations of concrete under biaxial stresses were based on the orthotropic model originally developed by Darwin and Pecknold (1977) combined with the biaxial failure criterion of Kupfer et al. (1969). Elastic-plastic behaviour with strain hardening was assumed for steel. The crack pattern was predicted from elastic analysis and a crack-link element was placed between two nodes on both faces of the crack. Poor bond was assumed on both crack faces, and perfect bond was assumed at some distance from the cracks.

\section{Olsen (Norway)}

Superposition of concrete and steel stiffness matrices was used. A nonlinear, elastic, biaxial, stress-strain relation was derived in terms of the two principal stresses. Elastic-plastic behaviour was assumed for the reinforcing steel. Tension stiffening was considered by reduction of average strains in the reinforcement.

\section{Pajari (Finland)}

The predicted failure stresses and stress-strain relations were evaluated by the computer program 


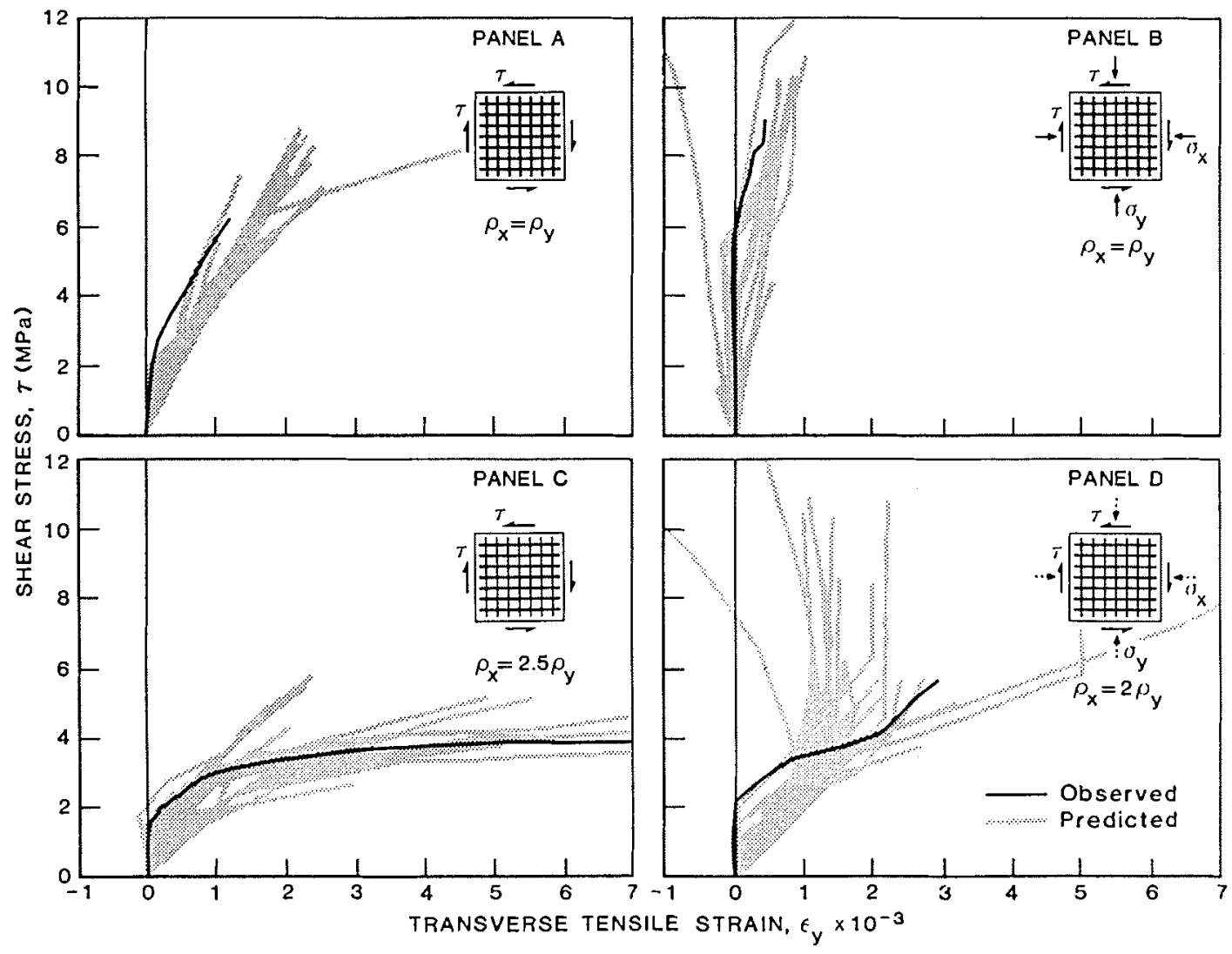

FIG. 11. Scatter in predicted transverse strains $\left(\epsilon_{y}\right)$.

ADINA (Bathe 1975) using a modified version developed at the Technical Research Centre of Finland (Pajari 1980). Isoparametric plane stress elements with eight nodes were used. The loading was modelled by point loads acting at the side nodes of the panel.

\section{Razaqpur and Ghali (Canada)}

Predictions of panel response were obtained using the finite element program FELARC, a program which traces the nonlinear behaviour of thin-plate elements subjected to in-plane forces and bending by a series of incremental linear analyses using the tangent stiffness approach. For this analysis, each finite element was represented by a quadrilateral in-plane element with 12 nodal degrees of freedom. The thickness of each element was divided into a number of concrete and smeared steel layers with orthotropic properties. Element stiffness was obtained by summing the stiffness contribution of individual layers. Full bond was assumed between concrete and steel throughout the analysis. For the concrete stress-strain relation, the equivalent uniaxial strain concept of Darwin and Pecknold (1977) was used, and the maximum concrete compressive strength was determined from the mod- ified biaxial failure envelope of Kupfer and Gerstel (1973). Reinforcement steel was modelled as elasticplastic with strain hardening. The smeared crack approach was adopted, and cracking was assumed perpendicular to the principal stress direction. Tensionstiffening effects were also taken into account.

\section{Reineck (Germany)}

Predictions were based on the truss analogy model of CEB MC78, and were performed by simple hand calculations. The inclination of the compression struts varied between $45^{\circ}$ and $26.7^{\circ}$. The compression field was idealized by resultant forces as well as by the loads. The concrete strength was considered to be independent of multiaxial stresses or strains; the failure strength in compression was taken as $0.76 f_{c}^{\prime}$.

\section{Schäfer (Germany)}

The prediction method chosen employed a plasticity model giving an upper-bound solution. Equilibrium was satisifed in sections parallel to the principal stresses, with allowances made for dowel action of the reinforcement. Compression strength of concrete was considered independent of multiaxial stress or strain, 


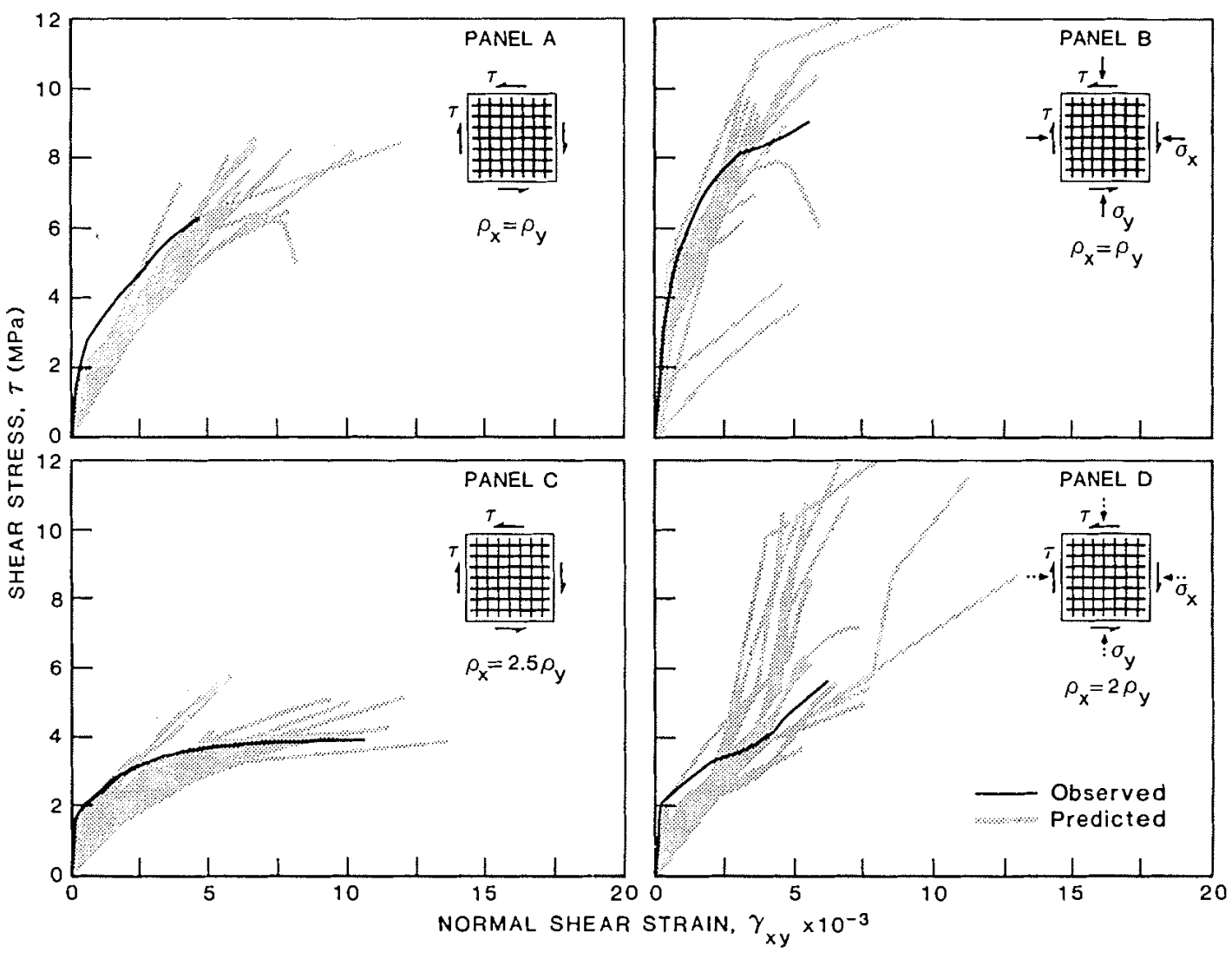

FIG. 12. Scatter in predicted normal shear strains $\left(\gamma_{x}\right)$.

and with no reduction of cylinder strength. In tension, the section failed if the reinforcement yielded across a crack orthogonal to the principal tensile stresses. Combined shear and tensile forces were assumed to be carried by the steel bars across the cracks.

\section{Schmidt-Gönner and Mehlhorn (Germany)}

Nonlinear finite element analyses were performed using the ADINA program. Concrete behaviour was based on a biaxial stress - strain model (Mehlhorn and Schmidt-Gönner I98I), including tension-stiffening effects. Bilinear response, with strain hardening $\left(E_{\mathrm{h}}=\right.$ $0.03 E_{0}$ ), was assumed for the reinforcement. Cracks were modelled using the 'smeared' approach, and the direction of primary cracks was assumed normal to the principal tensile stress. Dowel action of the reinforcement was neglected, and no reduction of the concrete thickness was considered, owing to the presence of reinforcement. Also, no reduction of the concrete strength was taken into account, owing to splitting action of the reinforcement, stress concentrations, or notch action.

Shirai (Japan)

Response of the panels was predicted using a non- linear finite element model. Nonlinear response of concrete in the compression region, including strain softening, was idealized by an elastic-plastic model of trilinear type based on the von Mises yield criterion (Shirai and Sato 1981). Concrete in the tension region was assumed elastic up to cracking stress; the MohrCoulomb criteria for cracking was used. Behaviour of the reinforcing bars was idealized by the perfectly elastoplastic model. The bond between steel and concrete was considered by using equivalent concrete stresses, aggregate interlock was considered by using an equivalent shear stiffness of concrete, and dowel action of reinforcing bars was also considered by using an equivalent shear stiffness of concrete. An incremental self-correcting approach was used in the analytical procedure. (Comment by author after the competition: A mistake was made in the recorded failure stress of panel $\mathrm{B}$; the correct predicted value is $8.06 \mathrm{MPa}$.)

\section{Walraven and Reinhardt (Netherlands)}

Predictions were based on plasticity theory, with the calculation of stresses made to satisfy static equilibrium. Failure conditions considered included yielding of reinforcement, crushing of concrete, and ultimate 


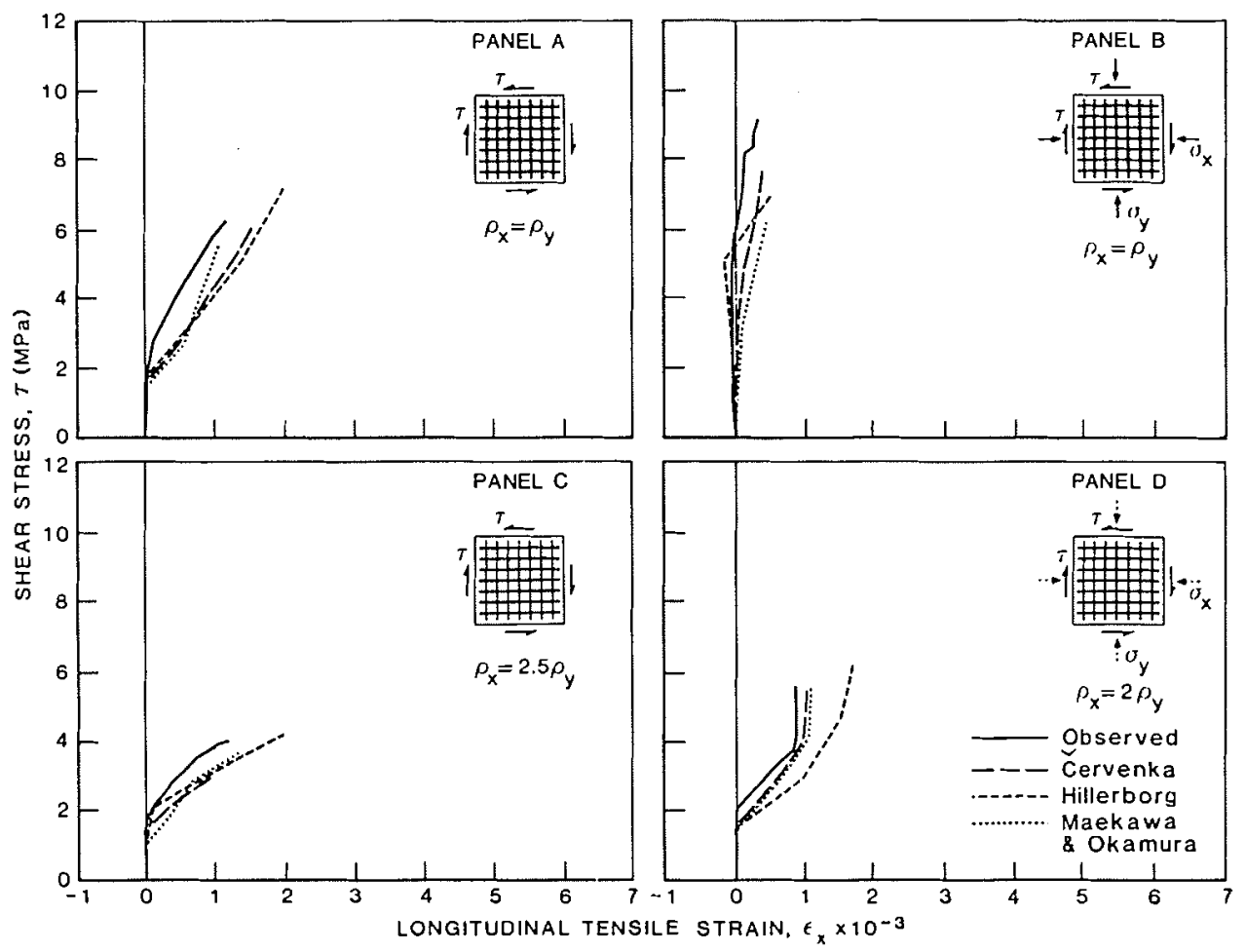

FIG. 13. Longitudinal strain predictions of three entries.

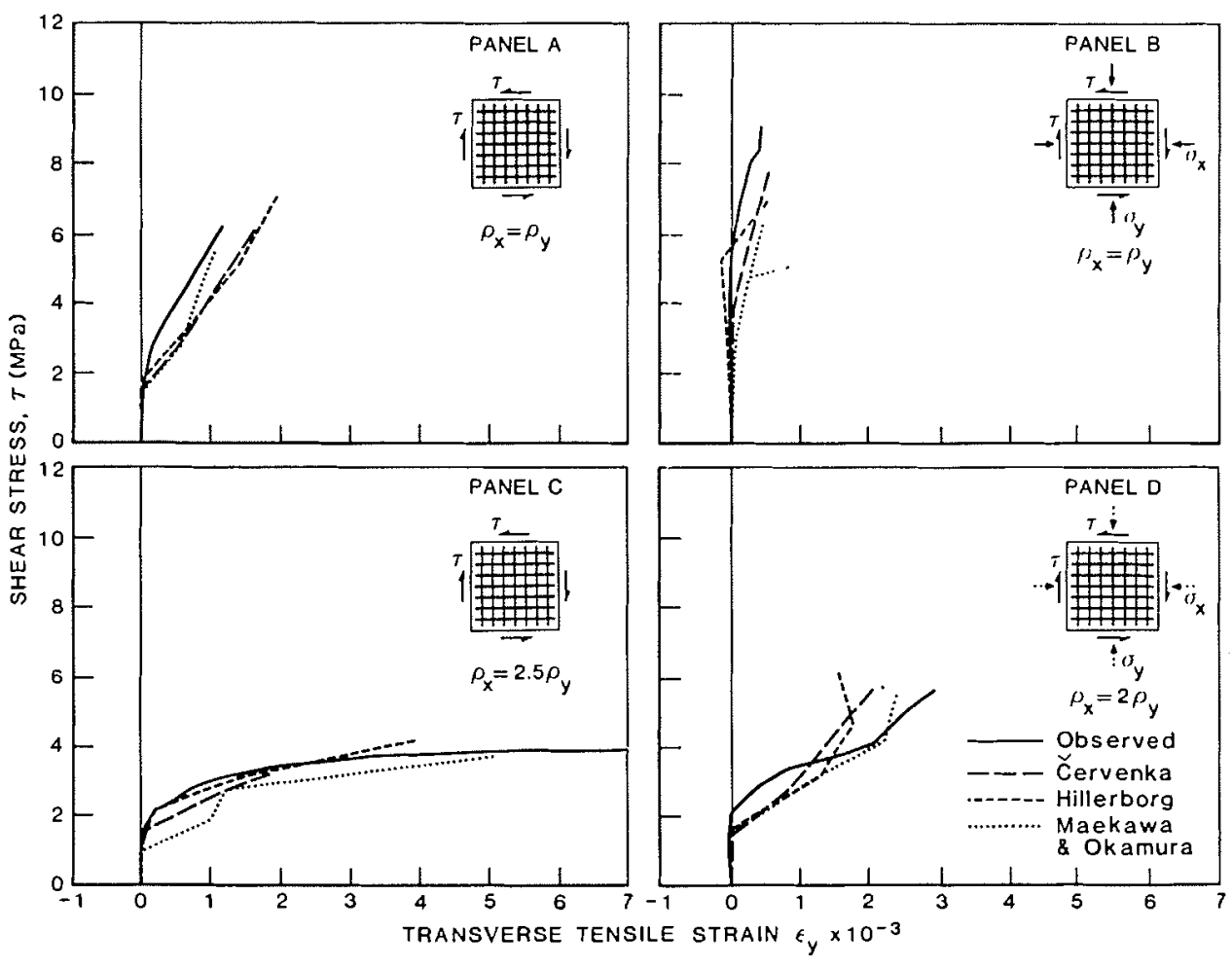

FIG. 14. Transverse strain predictions of three entries. 


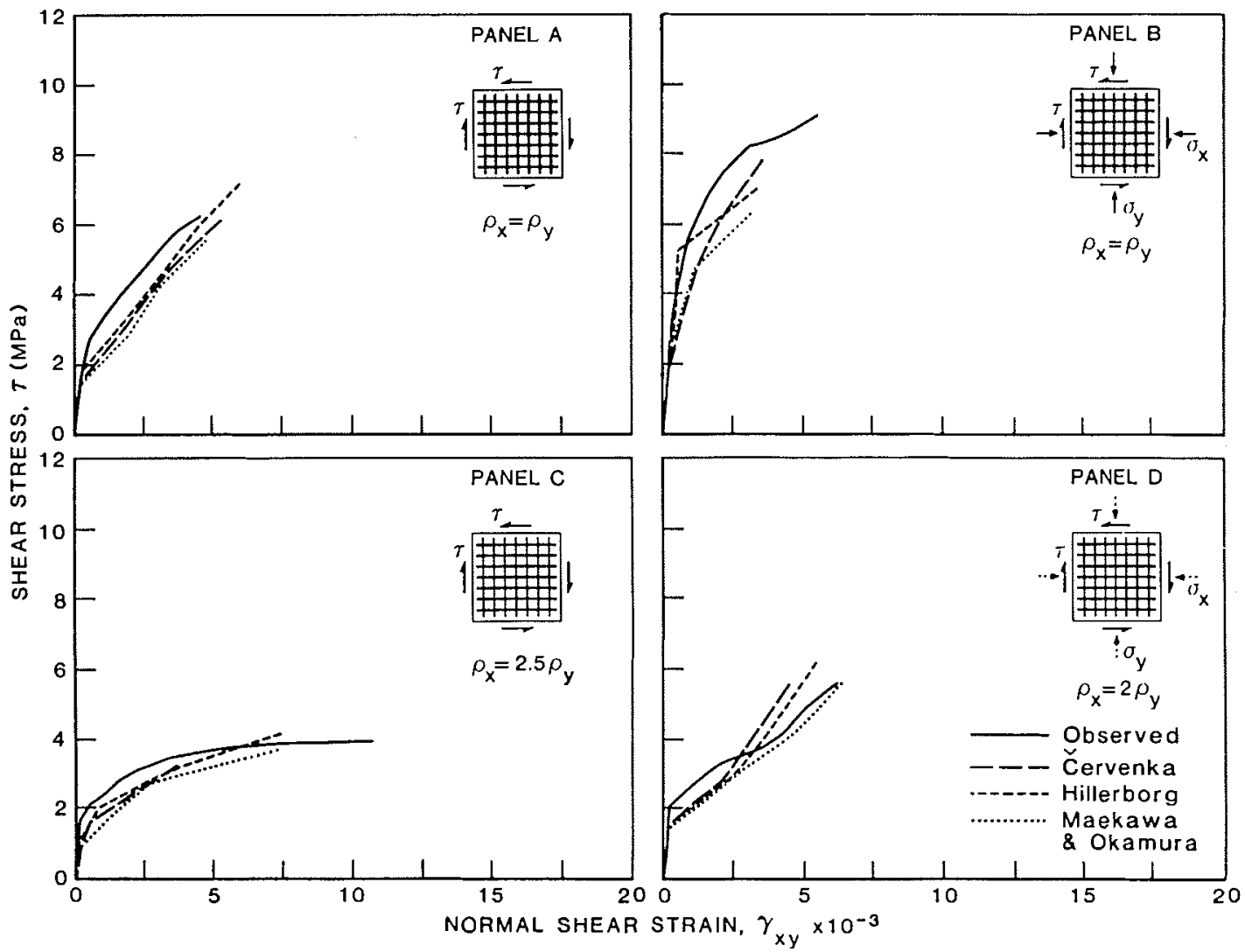

FIG. 15. Normal shear strain predictions of three entries.

capacity of interface shear in cracks. The crushing strength of concrete in a compression field was assumed to be $80-85 \%$ of the prism strength.

\section{Walter and Mang: (Austria)}

Analyses were based on the finite element program FESIA (finite element shell instability analysis) using a triangular, curved, thin-shell element with 33 degrees of freedom. Physical nonlinearity was considered by means of a material law for plane stress developed by Liu et al. (1972), based on test results by Kupfer (1969). The reinforcement was smeared to steel layers embedded in the concrete. Elastoplastic behaviour with strain hardening was assumed for the reinforcement, both in tension and compression. The solution procedure (Floegl and Mang 1981) considered fracturing of concrete, yielding of the reinforcement, and tension stiffening.

\section{Weischede (Germany)}

The simple hand-calculation method used was based on the assumption that the material was fully plastic and reached its specified strength limits. All tension forces were assumed taken by the reinforcement, with allowances made for tension-stiffening effects. The com- pression forces were taken by both the concrete and steel. The two material components formed a 'failure criterion;' by applying the Mohr's circles on both, an area was defined by their envelope. That stress circle that touched the envelope of the 'failure criterion' was assumed to be the most critical one, thus defining the required stress state. No reduction was applied to the concrete compressive strength compared with the cylinder strength.

BATHE, K. Y. 1975. ADINA, a finite element program for automatic dynamic incremental nonlinear analysis. Massachusetts Institute of Technology, Cambridge, MA, MIT Report 82448-7 (revised 1977).

Bažant, Z. P., and Gambarova, P. 1980. Rough cracks in reinforced concrete. ASCE Journal of the Structural Division, 106(ST4), pp. 819-842.

BAŽANT, Z. P., and OH, B. H. 1983. Deformation of cracked net-reinforced concrete walls. ASCE Journal of Structural Engineering, 109, pp. 93-108.

BAZZI, G. 1981. PIFF, a program for incremental formulation of finite element analysis in non-linear statics and dynamics. User handbook (internal report of ETH, Zürich).

ČERVENKA, V., and GERsTLE, K. H. 197I. Inelastic analysis of reinforced concrete panels, Part 1: Theory. Publications 
of the IABSE, Vol. 31-11

CHEn, A. C. T., and CHEN, W. F. 1975. Constitutive relations for concrete. ASCE Journal of the Engineering Mechanics Division, 101, pp. 465-481.

Darwin, D., and PECKNOLD, D. A. 1977. Nonlinear biaxial stress-strain law for concrete. ASCE Journal of the Engineering Mechanics Division, 103(EM4), pp. 229-241.

FLOEGL, H., and MANG, H. 1981. On tension stiffening in cracked concrete slabs and shells considering geometric and physical nonlinearity. Ingenieur-Archiv, 51, pp. $215-242$.

GUPTA, A. K., and AKBAR, H. 1981. Changing crack direction in reinforced concrete analysis. Report. North Carolina State University, Raleigh, NC.

Kotsovos, M. D. 1980. A mathematical model of the deformational behaviour of concrete under generalized stress based on fundamental material properties. Materials and structures, 13(76), pp. 289-298.

KUPFER, H. 1969. Das verhalten des betons unter zweiachsiger beanspruchung. Bericht Nr. 78, des Lehrstuhls für Massibau der TH München, München.

KuPfER, H. B., and Gerstle, K. H. 1973. Behaviour of concrete under biaxial stresses. ASCE Journal of the Engineering Mechanics Division, 99(EM4), pp. 853-866.

KuPFER, H. B., HILSDORF, H. K., and RÜSCH, H. 1969. Behaviour of concrete under biaxial stresses. Journal of the American Concrete Institute, 66, pp. 656-666.

LiU, T. C. Y., Nilson, A. H., and Slate, F. O. 1972. Biaxial stress-strain relations for concrete. ASCE Journal of the Structural Division, 98(ST5), pp. 1025-1034.

LINK, J. 1976. Eine Formulierung des zweiaxialen Verformungs - und Bruchverhaltens von Beton aund deren Anwendung auf die wirklichkeitsnahe Berechnung von
Stahlbetonplatten. Heft Nr. 270. Duetscher Ausschuss für Stahlbeton.

MAEKAWA, K. 1982. Constitutive model of concrete under biaxial stress states. Master thesis, Department of Civil Engineering, University of Tokyo, Tokyo.

MEHLHORN, G., and SchmidT-GönNER, G. 1981. A calculation of reinforced concrete beams under bending and torsion using three-dimensional elements. International Association for Bridge and Structural Engineering Colloquium, Delft, Final Report, pp. 597-602.

Niwa, J., Maekawa, K., and OKamuRa, H. 1981 . Nonlinear finite element analysis of deep beams. International Association for Bridge and Structural Engineering Colloquium, Delft, Final Report, pp. 335-350.

PAJARI, M. 1980. Program package for nonlinear analysis of reinforced concrete structures. Report 76. Technical Research Centre of Finland, Concrete and Silicate Laboratory, Espoo.

RossI, M., and BAzZI, G. 1981. Two simple reinforced concrete beam elements for static and dynamic analysis. International Association for Bridge and Structural Engineering Colloquium, Delft, Final Report, pp. 397-412.

SHIRAI, N., and SATO, T. 1981. Inelastic analysis of reinforced concrete shear wall structures-Applications and environmental verifications. International Association for Bridge and Structural Engineering Colloquium, Delft, Final Report, pp. 687-700.

VeCCHIO, F, and Collins, M. P. 1981. Stress-strain characteristics of reinforced concrete in pure shear. International Association for Bridge and Structural Engineering Colloquium, Delft, Final Report, pp. 211-225.

WaLRAVEN, J. C. 1980. Aggregate interlock: Theoretical and experimental analysis. Dissertation, Technological University of Delft, Delft, The Netherlands. 